NBER WORKING PAPER SERIES

\title{
CAPITAL FLOW MANAGEMENT MEASURES: WHAT ARE THEY GOOD FOR?
}

\author{
Kristin Forbes \\ Marcel Fratzscher \\ Roland Straub \\ Working Paper 20860 \\ http://www.nber.org/papers/w20860
NATIONAL BUREAU OF ECONOMIC RESEARCH
1050 Massachusetts Avenue
Cambridge, MA 02138
January 2015

Thanks to Anusha Chari, Kathryn Dominguez, Jeffrey Frankel, Marcio Garcia, Rex Ghosh, Graciela Kaminsky, Michael Klein, Maurice Obstfeld, Jonathan Ostry, Vincent Reinhart, Hélène Rey, Andy Rose, Klaus Schmidt-Hebbel, Silvia Sgheri, and James Yetman for extremely helpful suggestions and conversations. Further thanks for comments from other participants in conferences and seminars hosted by the Bank of Canada, Bank of Korea, Bank of Latvia, Banco de Mexico, Central Bank of Turkey, European Central Bank, International Monetary Fund, NBER, and New Zealand Central Bank and Treasury. Thanks to Bogdan Bogdanovic and Daniel Happ for excellent research assistance. The views expressed in this paper are those of the authors and do not necessarily reflect those of the ECB, the Eurosystem, any institutions with which the authors are affiliated, or the National Bureau of Economic Research.

NBER working papers are circulated for discussion and comment purposes. They have not been peerreviewed or been subject to the review by the NBER Board of Directors that accompanies official NBER publications.

(C) 2015 by Kristin Forbes, Marcel Fratzscher, and Roland Straub. All rights reserved. Short sections of text, not to exceed two paragraphs, may be quoted without explicit permission provided that full credit, including $(\mathcal{C}$ notice, is given to the source. 
Capital Flow Management Measures: What Are They Good For?

Kristin Forbes, Marcel Fratzscher, and Roland Straub

NBER Working Paper No. 20860

January 2015

JEL No. F3,F4,F5,G0,G1

\begin{abstract}
$\underline{\text { ABSTRACT }}$
Are capital controls and macroprudential measures related to international exposures successful in achieving their objectives? Assessing their effectiveness is complicated by selection bias; countries which change their capital-flow management measures (CFMs) often share specific characteristics and are responding to changes in variables that the CFMs are intended to influence. This paper addresses these challenges by using a propensity-score matching methodology. We also create a new database with detailed information on weekly changes in controls on capital inflows, capital outflows, and macroprudential measures related to international transactions from 2009 to 2011 for 60 countries. Results show that these macroprudential measures can significantly reduce some measures of financial fragility. Most CFMs do not significantly affect other key targets, however, such as exchange rates, capital flows, interest-rate differentials, inflation, equity indices, and different volatilities. One exception is that removing controls on capital outflows may reduce real exchange rate appreciation. Therefore, certain CFMs can be effective in accomplishing specific goals_-but most popular measures are not "good for" accomplishing their stated aims
\end{abstract}

Kristin Forbes

MIT Sloan School of Management

100 Main Street, E62-416

Cambridge, MA 02142

and NBER

kjforbes@mit.edu

Marcel Fratzscher

DIW Berlin

GERMANY

mfratzscher@diw.de
Roland Straub

European Central Bank

Roland.Straub@ecb.int 


\section{Introduction}

Over the last few years, economists and policymakers have become more supportive of "capital-flow management” measures (CFMs) to address the negative effects of large and volatile capital flows. This support has been bolstered by a series of IMF papers developing scenarios in which different CFMs should be "part of a policy toolkit", as well as a series of theoretical papers modeling how CFMs can increase social welfare. ${ }^{1}$ A number of countries have followed these recommendations and over 40 countries have adjusted their CFMs at least once from just 2009 through 2011. The stated purpose of these recent changes in CFMs includes: limiting exchange rate appreciation, reducing portfolio inflows, providing greater monetary policy independence, reducing inflation, reducing volatility, and/or reducing specific measures of financial fragility (such as bank leverage, credit growth, asset bubbles, foreigncurrency exposure, or short-term liabilities). But can CFMs accomplish any of these goals? If the answer is affirmative, CFMs could help stabilize economies experiencing substantial capital flow volatility driven by external factors (see Bluedorn et al., 2013).

CFMs refer to two types of measures: (1) capital controls or any types of restrictions on cross-border financial activity that discriminate based on residency; and (2) macroprudential measures which do not discriminate based on residency, but relate to cross-border or foreign-currency exposure and lending. This definition does not include prudential regulations targeting individual institutions or macroprudential regulations unrelated to cross-border exposure. ${ }^{2}$ Most papers have found little or mixed evidence that capital controls affect exchange rates, the volume of capital flows, monetary policy independence, and other macroeconomic variables, but stronger evidence that they can significantly affect the composition of capital flows and specific measures of financial vulnerability. ${ }^{3}$ The IMF writes that: "Because capital controls have been used many times in the past, evidence on their effects is more abundant but still surprisingly inconclusive.” (Blanchard et al., 2013, pg. 20) Empirical evidence on the effectiveness of macroprudential measures is even more limited, partially due to their infrequent use before 2009. The IMF admits that: "Empirical evidence on the effectiveness of these measures is scant...." (Blanchard et al., 2013, pg. 17)

\footnotetext{
${ }^{1}$ Key IMF papers are: IMF (2011a, 2011b, 2012) and Ostry et al. (2010, 2011). Key theoretical papers are: Korinek (2010, 2011), Jeanne and Korinek (2010), Costinot, Lorenzoni, and Werning (2011), and Jeanne (2012, 2013).

${ }^{2}$ See IMF (2012, page 40) for the "institutional” definition of CFMs. For example, this measure includes restrictions on exposure to mortgage debt denominated in foreign currency but does not include restrictions on exposure to mortgage debt based on loan-to-value or debt-to-income ratios.

${ }^{3}$ For recent surveys of this literature that show limited effects of capital controls, see Forbes (2007a), Cline (2010), Magud, Reinhart, and Rogoff (2011), Klein (2012), and IMF (2013). For more recent evidence that controls and macroprudential measures may improve a country's liability structure and increase its resilience to crises, see Ostry et al. (2012), Ostry et al. (2010), and IMF (2013). For mixed evidence from just Brazil's recent use of capital controls, see Forbes et al. (2012), Chamon and Garcia (2013), and Jinjarak et al. (2013).
} 
This inconclusive series of results is not surprising given major challenges in assessing the impact of capital controls and macroprudential measures: data limitations and selection bias (related to both timeinvariant country characteristics as well as time-varying values of outcome variables and other policy choices). Selection bias can occur because countries which adjust their CFMs tend to have different characteristics than other countries. For example, estimates in this paper show that countries with stronger institutions are significantly more likely to remove controls on capital outflows and increase macroprudential measures. A time-varying form of this bias can also occur because governments tend to adjust their CFMs in response to changes in key variables which the CFMs are intended to influence. For example, estimates in this paper show that countries are more likely to increase controls on capital inflows and reduce controls on outflows after a currency appreciation. This paper addresses these econometric challenges by using a propensity-score matching methodology. This methodology is fairly new to the macro and international economics literatures, but has been used for years in medical and labor economics. ${ }^{4}$ This methodology has a number of advantages over standard estimation techniques for the analysis in this paper, including its ability to avoid strong assumptions about functional form while addressing non-random sample selection by putting more weight on similar countries.

In order to analyze the impact of capital controls and macroprudential measures using propensity-score matching, it is necessary to construct a new database with information on CFMs at a higher frequency and for a larger sample of countries than previously existed. More detailed information is needed for this methodology in order to construct accurate control groups, as well as to capture all changes in capital controls and macroprudential measures. (In contrast, most other datasets only capture initial changes in CFMs, but not subsequent adjustments of similar measures.) Therefore, we compile detailed information on increases and decreases in controls on capital inflows, controls on capital outflows, and macroprudential measures at a weekly frequency for 60 countries from 2009 through 2011. We also divide our database into: measures aimed at stemming capital inflows/appreciation/credit growth or outflows/depreciation/credit contractions; capital controls affecting equities, bonds, or FDI; macroprudential measures targeting banks or foreign exchange; and CFMs that were "major" in the sense they received substantial attention by investors.

\footnotetext{
${ }^{4}$ See Rosenbaum and Rubin (1985) for background on this methodology and Angrist and Pischke (2008) for an excellent discussion and examples from the labor literature. Persson (2001) is the earliest application of this approach to macroeconomic, time series data. Differences between propensity-score matching and more traditional regression analysis, as well as recent examples in which propensity-score matching is starting to be used to address a international and macroeconomic topics, are discussed in Section 3.1 and Appendix C.
} 
Then we use this new database to estimate the probability that a country changes a particular type of capital control or macroprudential measure each week based on a set of observable domestic and global variables. We focus on predicting changes in CFMs directed at reducing pressures related to capital inflows (increased controls on inflows, decreased controls on outflows, and increased macroprudential regulations) as these were the primary tools utilized over the sample period from 2009 through 2011. These estimates provide intuitive results on which global variables, macroeconomic policies, and domestic characteristics influence a country's choice to adjust its CFMs. The estimates show that there are significant differences in the institutions and macroeconomic characteristics of countries that use these policies, and that key variables intended to be influenced by CFMs (such as exchange rates and credit growth) can significantly affect the probability of using each policy — confirming that it is crucial to account for selection bias in the analysis.

The results of these logit models are then used to estimate propensity scores - the probability that each country changes its CFMs in each week as a function of observable variables. Another crucial advantage of the methodology is that it allows us to include a large number of observable variables and therefore be agnostic about the underlying model. PSM basically reduces the many potential observables that may influence the choice of whether or not a country adjusts a CFM to a single dimension captured in the propensity score. These propensity scores are used to match each member of the "treated group” (countryweek observations with changes in CFMs) with a control group (country-weeks with no changes in CFMs). We use five different algorithms to perform this matching (nearest-neighbor without replacement, five-nearest neighbors, radius, kernel, and local-linear) and report a series of tests evaluating if they satisfy key assumptions. Then we use these matched samples to estimate the average treatment effect on the treated (ATT) of each of the capital controls and macroprudential measures on a series of outcome variables. We estimate the cumulative effects for each week over a six-month window (or longer) on variables that are frequently cited as goals for adjusting CFMs: the exchange rate, portfolio flows, other macroeconomic variables (interest-rate differentials, equity markets, and inflation), financial market volatilities (for the exchange rate, portfolio flows, and interest rates) and other financial vulnerabilities (private credit growth, bank credit growth, inflation expectations, bank leverage, and exposure to shortterm external debt, portfolio liabilities, and foreign-currency liabilities).

The results indicate that CFMs have significant effects on some of the variables which they are intended to influence-although most effects are insignificant, small in magnitude, and not robust across matching methodologies. The strongest and most robust effects of CFMs appear to be of increased macroprudential regulations on reducing certain measures of financial vulnerability. Increased macroprudential measures 
significantly reduce bank leverage, inflation expectations, bank credit growth, and exposure to portfolio liabilities relative to the counterfactual (although the effect on portfolio liabilities reverses within a year). Increased controls on capital inflows reduce private credit growth over several months.

In contrast to these robust results, there is more limited evidence that CFMs affect other primary goalsincluding exchange rates and net capital flows. Changes in capital controls and macroprudential measures do not significantly affect aggregate portfolio flows or nominal or real exchange rates. ${ }^{5}$ The one exception is that removing controls on capital outflows can generate a significant depreciation of the real exchange rate-although the maximum estimated effect is a depreciation of less than 2.5\% over 4 to 6 months relative to the counterfactual. There is also no evidence that changes in CFMs significantly affect other macroeconomic variables and financial market volatilities over the short- and medium-term, including equity returns, inflation, interest-rate differentials versus the United States, or the volatility of exchange rates, portfolio flows, or interest-rate differentials. ${ }^{6}$ By improving specific measures of financial fragility, however, macroprudential measures may indirectly affect these macroeconomic variables and financial volatilities over longer periods of time.

These results have important implications. Much of the recent debate on the use of CFMs to reduce exchange rate appreciation has focused on the use of controls on capital inflows. The results in this paper, however, indicate that removing controls on capital outflows (at least for countries which have preexisting controls) may be a more effective tool for systematically limiting exchange rate appreciation. Also, the debate on the use of capital controls (and to a lesser extent macroprudential measures) has historically focused on affecting the exchange rate, capital flows, and other macroeconomic variables. Only recently has the debate shifted toward using these tools to reduce other forms of financial vulnerability (i.e., Ostry et al., 2012). The evidence suggests that this new focus is likely to be more productive. Moreover, macroprudential regulations appear to be more effective than capital controls in improving most measures of financial stability, albeit with the important caveat that the distinction between these two categories is often difficult to make. Therefore, CFMs, and especially macroprudential measures, appear to be "good for” addressing specific variables related to financial fragility, but do not appear to be as effective in influencing other targets.

\footnotetext{
${ }^{5}$ Although we do not find systematic evidence that controls on capital inflows can influence capital flows or exchange rates, this does not imply that such controls can never work. In fact, Forbes et al. (2012) find that Brazil's taxes on portfolio inflows from 2008 to 2011 significantly reduced equity inflows into Brazil. Section 4.2 tests if specific types of CFMs or CFMs in certain countries had different effects than CFMs in general.

${ }^{6}$ The one exception is that increased macroprudential regulations may reduce interest rate differentials for short periods of time by a small amount and may actually increase-instead of decrease — the volatility of portfolio flows.
} 
These results, however, should be assessed with several important caveats. First, the analysis is only able to consider the short- and medium-term effects of capital-flow management measures. We do not evaluate any effects after six months due to limits of the estimation technique. It is certainly possible that capital controls - especially macroprudential measures—-have additional effects after this six-month window that will not be captured in the analysis. Second, although the paper finds several significant benefits of capital-flow management measures, and especially macroprudential measures, in reducing some forms of financial fragility, the analysis does not make any attempt to assess the costs of these measures.

Macroprudential regulations and capital controls will involve certain costs, and a full cost-benefit analysis should be applied before implementing these policies. Finally, although our results imply that capital controls and macroprudential measures are not "good for" accomplishing many of their stated goals, it is possible that the apparent lack of effectiveness results from the policies being poorly enforced, poorly calibrated, poorly communicated, poorly timed, or poorly implemented in any other way. As these tools are more widely used and better understood, they could be more effective in the future.

The remainder of this paper is as follows. Section 2 describes the new dataset on changes in capital controls and macroprudential measures created for this paper. Section 3 discusses the propensity-score methodology, uses this methodology to estimate the probability that each country adjusts its CFMs, and then uses these estimates to calculate propensity scores to match each "treatment” with its control group. This section also evaluates the performance of each of the matching algorithms. Section 4 uses the matched groups to estimate the effects of CFMs on key outcome variables and includes a series of extensions and robustness tests. Section 5 concludes.

\section{Capital-Flow Management Events and Dataset}

In order to construct a database of capital-flow management events that allows us to evaluate the systematic effects of CFMs and that includes a large enough sample to use propensity-score matching effectively, we compile data on both capital controls and macroprudential measures at a weekly frequency for a larger set of countries than is typically used in this literature. ${ }^{7}$ More specifically, we begin with all “Advanced Economies” (as defined by the International Monetary Fund as of October 2012) and all “Emerging Markets” and “Frontier Economies” (as defined by Standard \& Poor’s BMI indices). We then

\footnotetext{
${ }^{7}$ The most well-known databases on capital controls are Chinn and Ito (2008) and Schindler (2009), which is updated in Klein (2012). These use annual dummy variables to measure the existence of different types of capital controls and therefore do not capture many changes in controls. Recent studies with information on both capital controls and macroprudential measures are Pasricha (2012) and Ostry et al. (2012), which is expanded on in Beirne and Friedrich (2013). These datasets are also only at an annual frequency and for a more limited set of countries.
} 
exclude current members of the euro area, the three largest advanced economies (the United States, United Kingdom, and Japan) and countries that do not have data on equity or bond flows. This yields a sample of 60 countries for our analysis, with additional information on sample selection and the final list of countries listed in Appendix A.

Next, we use several sources to document weekly changes in CFMs during 2009, 2010, and 2011 for this sample of 60 countries. Our primary source is the Annual Report on Exchange Arrangements and Exchange Restrictions by the International Monetary Fund. We supplement this source with information from financial analyst reports, primary news sources, and academic papers on capital controls and macroprudential measures. The crucial criterion for including a policy as a change in capital controls or macroprudential measures is that it places any type of restriction on cross-border financial activity based on residency or cross-border or foreign currency exposures. We classify the selected measures into three major groups - controls on capital inflows, controls on capital outflows, and macroprudential measures. These classifications require some discretionary judgment, especially as the distinction between capital controls and macroprudential measures is often not clear in practice.

More specifically, we define capital controls as measures that limit or restrict international capital transactions or that affect the transfers and payments associated with these transactions. Typical measures include taxes on cross-border flows from residents/non-residents, unremunerated reserve requirements (URR) on such flows, special licensing requirements, and even outright limits or bans on international transactions. Capital controls may apply to all cross-border financial flows, or may differentiate by the type or duration of the flow (i.e., debt, equity, or direct investment; short-term vs. longer-term). Macroprudential measures are defined as regulations focused on strengthening the ability of the overall domestic financial sector to cope with risks related to foreign exchange or international exposure. These measures do not directly target capital flows, but instead the balance-sheet risk which could result from these flows. Therefore, they often focus on the currency of the transaction or exposure, instead of the residency of the parties to the transaction. They commonly consist of limits on banks' open foreignexchange (FX) position, limits on banks' investments in FX assets, and differential reserve requirements on liabilities in local currency and FX. Our measure does not include other macroprudential regulations which are purely domestic and not related to cross-border exposure (such as on domestic mortgage lending). Appendix A provides specific examples of the types of measures which are (and are not) included in our definitions, as well as additional information on the database. 
After constructing this database of changes in controls on capital inflows, controls on capital outflows, and macroprudential measures, we then further differentiate these CFMs by several criteria. We label each change in a CFM as an increase or decrease—with an increase meaning a new or stricter regulation and a decrease implying the removal or reduction in a regulation. We also classify each measure as affecting: equities, bonds/fixed income, foreign direct investment (FDI), loans, banks, and/or FX. In some cases, a CFM may simultaneously affect more than one of these categories. ${ }^{8}$ CFMs affecting equities, bonds, and FDI are more often capital controls, and CFMs affecting banks, foreign exchange, and loans are more often macroprudential measures—but this division does not always hold. Finally, we also construct a variable classifying a CFM as “major” or not, based on whether it received attention by financial analysts and investors. (This variable is discussed in Section 4.2.)

The resulting database includes 220 CFM events. Out of the 60 countries in the sample, 39 countries have at least one event during the period from 2009 to 2011. Table 1 lists the number of inflow controls, outflow controls, and macroprudential measures that were increased/added or decreased/removed by each country. It shows that mainly emerging markets and developing countries implemented changes in controls or macroprudential measures over this period, with only a few changes in advanced economies (such as the Czech Republic, Israel, South Korea, and Taiwan). The sample has more changes in macroprudential measures (121 events) than capital controls (99 events)—with the changes in capital controls evenly balanced between changes in controls on inflows (50 events) and outflows (49 events). The CFM events are also more heavily weighted toward policies affecting bonds (67) and equities (47) than FDI (18), and more often focus on foreign exchange (130) and banks (107) than loans (46). Our review of analyst comments indicates that 44 of the measures were viewed as “major" by investors.

It is also possible to divide the CFM events into two groups-those responding to pressures related to large net capital inflows and those related to net outflows. More specifically, countries concerned about strong net capital inflows, currency appreciation, rapid credit growth, and related vulnerabilities can choose between increasing controls on capital inflows, reducing controls on capital outflows, and/or increasing macroprudential regulations. Countries concerned about sudden stops, currency depreciation, a contraction in credit, and/or related vulnerabilities can choose between decreasing controls on capital inflows, increasing controls on capital outflows, and/or decreasing macroprudential regulations. Figure 1 and the right-hand columns of Table 1 show the incidence of changes in these two groups of CFMs from 2009 through 2011. The sample is weighted more heavily towards CFMs aimed at moderating capital

\footnotetext{
${ }^{8}$ For example, a CFM affecting banks' reserve requirements for foreign currency deposits would be classified as a CFM affecting banks and FX.
} 
inflows (with 135 events compared to 85 with the opposite goal). This is not surprising as most of the period from 2009 through 2011 was a period of declining risk aversion, expansionary monetary policy in developed countries, and increasing global capital flows. In the analysis which follows, we focus on the impact of this larger group of CFM events aimed at moderating capital inflows and which have received the greatest attention by policymakers. ${ }^{9}$

Our new dataset on CFM events is then merged with information from several different sources to create the final database for this paper. Weekly market information on global risk (the VIX and TED spread), commodity prices, interest rates (overnight and on 3-monthTreasuries), equity market indices, and the nominal exchange rate is taken from Datastream, Global Financial Data, Haver, and JPMorgan. Weekly capital flow data on equity and bond flows and asset positions (adjusted for valuation changes) is taken from Emerging Portfolio Fund Research (EPFR). Monthly macroeconomic information on real exchange rates, private credit, foreign exchange reserves, GDP, CPI inflation, and GDP per capita is taken from the IMF and supplemented with data from the ECB as needed. Monthly measures of institutional quality are measured by the legal compliance index taken from the ICRG database. Information on a country's exchange rate regime is the de facto arrangement as measured in Ghosh et al. (2011), and information on past capital account openness is from Chinn and Ito (2008, updated as of 04/24/2013). Other information on stock market capitalization, country financial exposure, and liabilities is from the World Bank’s Global Financial Development Database (and in some cases supplemented by the ECB). Detailed information on this data, including sources and definitions, is in Appendix B.

\section{Propensity-Score Methodology, Estimating Scores, and Matching}

To estimate the impact of the CFMs, we use a propensity-score matching methodology. This section begins by summarizing this methodology. Then it uses a broad vector of observable variables to estimate a logit model of each country's choice to use each type of CFM each week. The section ends by using the resulting estimates to calculate propensity scores and match each "treatment” with a control group. The next section uses these matched groups to estimate the effects of the CFMs on outcome variables.

\subsection{Propensity-Score Matching Methodology}

Countries that adjust their capital controls and/or macroprudential measures are often different from countries which do not make these policy choices. This selection bias or "non-random assignment” makes

\footnotetext{
${ }^{9}$ We have also extended the analysis to other CFM measures related to concerns about capital outflows, currency depreciations, and related pressures (i.e., lifting controls on capital inflows and macroprudential measures and increasing controls on capital outflows). The more limited set of observations and global economic trends during the sample, however, complicate the analysis.
} 
it difficult to assess whether differences in key outcome variables between countries that undertake these policies and those that do not are driven by the policies or simply by underlying differences in the two sets of countries. One approach for adjusting for this selection bias is to use propensity-score matching. ${ }^{10}$ Persson (2001) provides compelling evidence of how propensity-score methodology can overturn standard cross-country regression results when countries which follow certain policies are systematically different than those which do not. This methodology has several advantages over standard regression methodology for this paper's analysis and is summarized below. Appendix C, however, provides more details on the methodology, as well as concrete examples of how selection bias is a challenge for the analysis of CFMs and may not be satisfactorily addressed with standard regression techniques.

To use the propensity-score methodology, define a "treated" observation as $D_{i}=1$, which is any week in which country $i$ changes a CFM. Likewise $D_{i}=0$ are the "untreated" or "control” observations, which are any weeks when country $i$ does not change a CFM. We also create an "exclusion window" for 3 months before and 3 months after a change in the CFM of interest. ${ }^{11}$ During this exclusion window, a country cannot be used as a control observation - even if it makes no changes to the relevant CFM during those weeks. Also define $Y_{1, i}$ as the outcome variable (such as the change in the exchange rate) for the $i^{\text {th }}$ member of the treated group and $Y_{0, i}$ for the $i^{\text {th }}$ member of the untreated (control) group. Summing over members of each group, we are able to observe $\mathrm{E}\left[Y_{1, i} \mid D_{i}=1\right]$ and $\mathrm{E}\left[Y_{0, i} \mid D_{i}=0\right]$. The variable in which we are interested, however, is the "average treatment effect on the treated" or ATT, which is not observable and is written as:

$$
\mathrm{ATT}=\mathrm{E}\left[Y_{1, i}-Y_{0, i} \mid D_{i}=1\right]
$$

The difference in the two observable statistics is a combination of the key variable of interest (the ATT) and sampling bias $\left(\mathrm{E}\left[Y_{0, i} \mid D_{i}=1\right]-\mathrm{E}\left[Y_{0, i} \mid D_{i}=0\right]\right)$. This sampling bias is the difference in outcomes that is

\footnotetext{
${ }^{10}$ See Dehejia and Wahba (2002) and Angrist and Pischke (2008, chapter 3) for excellent summaries of this methodology. Also see Heinrich, Maffioli, and Vazquez (2010) for a non-technical overview. This technique is just starting to be used in the international/macro/monetary economics literature. Recent examples are: Angrist and Kuersteiner (2011) and Angrist, Jordá, and Kuersteiner (2013) on monetary policy; Glick, Guo, and Hutchison (2006), Das and Bergstrom (2012), and Levchenko, Rancière, and Thoenig (2009) on financial liberalization; Chari, Chen, and Dominguez (2011) on foreign ownership; Forbes and Klein (2013) on crisis responses; and Jordà and Taylor (2013) on fiscal policy.

${ }^{11}$ This exclusion window prevents labelling countries which recently changed or are about to change a CFM as a control observation. It also prevents matching treated observations for one country with control observations for the same country at slightly different points in time. Moreover, given the many factors which determine when a change in a CFM occurs, we do not expect to be able to predict the exact week in which a change is made. We focus on a 3month exclusion window, as Forbes et al. (2012) find that changes in Brazil's capital controls from 2009 to 2011 can affect capital flows for more than a month, but no longer than 3 months.
} 
attributable to differences in the treated and control group (such as different country characteristics) rather than any effect of the treatment itself. Any sampling bias between the treated and control groups would be straightforward to adjust for if the units $i$ differed along one or two discrete and measurable dimensions. This is not feasible, however, when comparing countries which vary across a number of dimensions.

Propensity-score matching can address this challenge. This methodology matches countries that undertake the treatment (i.e., policy change) to a subset of countries that do not, based on a set of observable country characteristics, represented by the vector $X_{i}$ for the $i^{\text {th }}$ country. Moreover, Rosenbaum and Rubin (1985) show that it is sufficient to match treated and control observations based on a “propensity score,” $p\left(X_{i}\right)$, which is a scalar variable that is the probability that country $i$ receives the treatment $\left(D_{i}\right)$. More specifically, the propensity score, $p\left(X_{i}\right)$ is:

$$
p\left(X_{i}\right)=\operatorname{Pr}\left[D_{i}=1 \mid \mathrm{X}_{\mathrm{i}}\right]
$$

In our case, the propensity score is the conditional probability of a country adjusting its CFMs given pretreatment characteristics, $X_{i}$, which include country-specific and global variables.

After the propensity scores have been estimated, there are several algorithms that can be used to match each treated observation with the controls. We focus on five matching algorithms, each of which has advantages and disadvantages. There are several tests to assess the accuracy of the matching and whether the algorithm removes significant differences between the treated and control groups. These tests and statistics are discussed in more detail in Section 3.3 when they are used. If these tests are satisfied, it is then possible to estimate the ATT as:

$$
\mathrm{ATT}=\mathrm{E}\left[Y_{1, i} \mid D_{i}=1, p\left(X_{i}\right)\right]-\mathrm{E}\left[Y_{0, i} \mid D_{i}=0, p\left(X_{i}\right)\right]
$$

The ATT in equation 3 is the estimated treatment effect from the change in capital controls or macroprudential measures after controlling for selection bias.

To conclude, it is useful to mention how this approach compares to the more familiar regression analysis based on OLS. Multivariate regressions estimate the partial correlation of the treatment with the outcome variable and can control for the other variables included in the vector $X_{i}$. Multivariate regressions can also be combined with instrumental variables—although finding "good instruments" that meet the exclusion restrictions is often challenging. One important advantage of propensity-score matching over 
multivariate regression analysis, however, is that matching does not require assumptions about a linear relationship between the treatments, covariates, and outcomes. Propensity-score estimation puts greater emphasis on modeling the policy change (the changes in CFMs), and it is not necessary to assume any functional form between any of the variables and the outcomes. This is particularly useful when the underlying model is unclear, including with respect to uncertain lag length, simultaneity, and endogeneity. Moreover, this methodology allows the inclusion of a large set of observable variables to determine the propensity score. This is particularly useful for our estimation as there is little theoretical guidance on exactly which variables should be included in the model. Although these advantages have been well-known in cross-section analysis, Angrist and Kuersteiner (2011) estimate the impact of monetary policy shocks and demonstrate that these advantages of propensity-score methodology are also useful in time-series, cross-section models, including in the presence of endogeneity and simultaneity.

Another important difference between standard regression analysis and the propensity-score methodology is the weighting of the observations in the control group. ${ }^{12}$ In both approaches, it is necessary to construct weights for the difference between treated and untreated values in order to calculate the average effect for the whole sample. In propensity-score matching, the greatest weights are put on observations representing the highest likelihood of being treated but weren’t (i.e., the control observations most "similar" to the treated observations). In contrast, in regression analysis the greatest weights are placed on observations where the conditional variance of treatment status is larger (i.e., basically those observations with equal likelihood of being treated or untreated) — which may be observations that are not very "similar" to those in the treated group. These two different weighting approaches can significantly affect the estimated average treatment effects. Put slightly differently, propensity-score matching will tend to reduce bias in the estimates by including a more relevant set of control observations, although it can also increase the variance due to the smaller number of observations in the control sample.

Although propensity-score matching has a number of advantages over standard regression analysis for certain types of analysis, it also has several disadvantages and criteria which must be satisfied. A major challenge for much of the international/macroeconomic literature is having a sufficient number of "similar" observations to form a control group; this criteria is unlikely to be met in standard crosscountry, annual datasets which only have data on the key "observable” variables for a limited set of

\footnotetext{
${ }^{12}$ Angrist and Pischke (2008, Chapter 3) provide an excellent discussion of the similarities and differences between regression analysis and propensity-score matching. Also, although propensity-score matching can reduce asymptotic efficiency relative to a regression framework, Angrist and Hahn (2004) show that there can be efficiency gain in a finite sample, even if there are no asymptotic efficiency gains. Given the small size of our sample-this suggests that this potential drawback of the propensity-score methodology is less likely to be an issue.
} 
countries and years. A second, and related, challenge is satisfying the balancing or independence assumption (discussed in more detail below). A third issue is that results can be sensitive to the matching methodology — thereby requiring robustness checks. A final challenge is incorporating the time-series dimension in the analysis-which may require some type of "exclusion window" around the treatment date (as discussed below).

To provide a concrete example of the different results that can be obtained using propensity-score matching relative to standard regression analysis in the presence of selection bias, consider a simple example of how macroprudential regulations affect the real exchange rate. The first column of Table 2 shows results of a regression estimating if increased macroprudential regulations relating to international transactions affect the percent change in the real exchange rate over the subsequent quarter. The positive and significant coefficient suggests that countries which increase these types of macroprudential regulations are more likely to have a significant real exchange rate appreciation (when not controlling for selection bias or other variables). As documented in Appendix C, however, countries which increase these macroprudential regulations are also more likely to have flexible exchange rates. Could this positive coefficient instead reflect differences between the types of countries which increase macroprudential regulations (selection bias) rather than an effect of regulations on the exchange rate?

To test if the positive relationship between macroprudential regulations and subsequent exchange rate appreciation is caused by differences in exchange rate regimes or other omitted variables, standard regression analysis would add variables to the regression to control for these variables. Results, controlling for if the country has a floating exchange rate, and then the full set of control variables used later in this paper, are reported in columns 2 and 3 in Table $2 .{ }^{13}$ Increasing macroprudential regulations still has a positive and significant effect on the real exchange rate (although the coefficient is only significant at the $10 \%$ level with the full set of controls variables). In contrast, a propensity-score methodology would divide the sample into groups of "more similar" countries, based on variables such as the country's exchange rate regime, and then only estimate the effect of macroprudential regulations relative to similar countries. The analogy in the simple framework in Table 2 would be the estimates in columns 4 through 7 . These estimates show that when only countries with flexible exchange rates are included in the regression, there is no longer any significant effect of increased macroprudential regulations on the exchange rate (with and without the full set of control variables). Countries that do NOT have a flexible exchange rate show a positive and significant relationship. This indicates that the positive impact of macroprudential measures on the real exchange rate estimated using standard OLS in

${ }^{13}$ Dummy variable indicating if a country has a floating exchange rate is from Ghosh et al. (2011). 
columns 1 through 3 could result from selection bias related to a country's exchange rate regime. (This is confirmed in the full analysis using propensity-score matching in Section 4.1.) Propensity-score methodology puts greater weight on more similar countries and is therefore better able to adjust for these different relationships for countries with different types of exchange-rate regimes than simply including control variables in a standard OLS framework.

\subsection{First-Stage Logit Regressions and Propensity Scores}

In order to calculate the propensity scores predicting the probability a country changes its CFMs as specified in equation 2, we draw from the literature on the determinants of capital flows and capital controls. ${ }^{14}$ Since our database on capital controls and macroprudential measures has a weekly frequency, we focus on covariates available at this frequency whenever possible. First, to control for changes in a country's exchange rate and capital flows, we control for percent changes in the country's real effective exchange rate and net portfolio inflows (over the last six months). Second, to control for increased inflation risk and credit growth—other reasons frequently cited as motivations for CFMs—we control for consensus CPI inflation forecasts and the percent change in private credit relative to GDP.

Third, to control for common changes in global sentiment and relative rates of return (including the effects of monetary policy in developed economies) that could affect global capital flows, we control for global risk (measured by the VIX and the TED spread), commodity prices (measured by percent changes in the Dow Jones commodity price index), and changes in the interest-rate differential between each country and the United States (on 3-month Treasuries). ${ }^{15}$ Fourth, to control for different intervention strategies, exchange rate regimes, and past use of CFMs, we include the percent change in foreign exchange reserves to GDP, a dummy equal to one if the country has a floating exchange rate, and the Chinn-Ito measure of the country's pre-existing capital account openness. Finally, to control for any effect of the size of a country's financial sector, income level, and institutional strength, we also control for stock market capitalization (as a share of GDP), GDP per capita (in logarithmic form), and the country's "legal compliance". ${ }^{16}$ For each variable measured in changes (or percent changes), we calculate the change in the variable relative to the previous year in order to minimize any seasonal effects. We also

\footnotetext{
${ }^{14}$ See Aizenman and Pasricha (2013) for empirical evidence on determinants of a country's use of controls on capital outflows and Fratzscher (2012) for evidence related to a country's use of controls on capital inflows. See Lim et al. (2011) for the determinants of a country's use of macroprudential measures.

${ }^{15}$ Rey (2014), Forbes and Warnock (2012), and Fratzscher (2012) provide empirical evidence on the importance of global risk in determining capital flows. Fratzscher, Lo Duca, and Straub (2012) provide evidence of the role of U.S. monetary policy.

${ }^{16}$ Lim et al. (2011) highlight the importance of the size of existing financial markets. Habermeier et al. (2011) discuss how institutional features, such as administrative capacity and legal compliance, could also have an effect on the design and enforcement of CFMs.
} 
lag all variables so that any change in the CFM occurs after the variable is measured. ${ }^{17}$ All variables are explained in detail in Appendix B. ${ }^{18}$

Therefore, our base regression used to explain changes in CFMs aimed at moderating capital inflows and related pressures from 2009 to 2011 can be written as:

$$
\operatorname{Prob}\left(C F M_{i t}=1\right)=F\left(\boldsymbol{\Phi}_{i, t-1}^{\text {Domestic }} \mathbf{B}_{\mathrm{C}}+\boldsymbol{\Phi}_{t-1}^{\text {Global }} \mathbf{B}_{\mathrm{G}}\right),
$$

where $C F M_{i t}$ is a dummy variable that takes the value of 1 if country $i$ changes its CFM (increases controls on capital inflows, decreases controls on capital outflows, or increases macroprudential measures) during week $t$; $\boldsymbol{\Phi}_{t-1}^{\text {Global }}$ is a vector of global variables (common shocks) lagged by one week (the VIX, TED spread, commodity prices, and the interest-rate spread); $\boldsymbol{\Phi}_{i, t-1}^{\text {Domestic }}$ is a vector of variables measuring domestic country characteristics. Domestic country characteristics include changes in key macroeconomic variables (the exchange rate, capital flows, inflation expectations, private credit, and reserves) and level variables measuring country characteristics which change less frequently (the exchange rate regime, capital account openness, financial market development, income per capita, and institutional strength). It is worth noting that these controls include variables capturing changes in policies other than CFMs that countries could select during this era of strong capital inflows, such as changes in exchange rates, interest rates, and reserve accumulation (i.e., other aspects of the trilemma). The regression is estimated using a logit model with robust standard errors. ${ }^{19}$

The resulting estimates of equation 4 for our sample of 60 countries are reported in Table 3. Many of the variables expected to affect the probability that a country modifies a CFM are significant and have the expected sign, although the covariates play differing roles for the three types of CFMs. Focusing on variables that are significant at the 5\% level, countries are significantly more likely to increase inflow controls and decrease outflow controls if they have had greater real exchange rate appreciation. Countries

\footnotetext{
${ }^{17}$ The six-month exclusion window around a change in a CFM (three months before and after the treatment date) as well as the one-period lag of all explanatory variables should reduce the likelihood that the explanatory variables are influenced by the introduction or anticipation of the CFMs. Forbes et al. (2012) find no evidence that markets reacted in advance to recent changes in Brazil's tax on capital inflows.

${ }^{18}$ We have also controlled for other variables — such as changes in equity indices, CPI inflation, the money supply (M1), and expected GDP growth. None of these variables is significant in any of the specifications and including them does not alter any of the main results. We have also used other measures for key variables - such as the nominal exchange rate instead of real exchange rate and the spread on overnight interest rates (instead of threemonth Treasuries). These changes also do not affect the key results, so we focus on measures that maximize the sample size.

${ }^{19}$ We focus on a logit instead of probit model in order to "spread out" the density of scores at very low and high propensity scores.
} 
are significantly more likely to increase macroprudential measures if they have had higher inflation expectations, greater private credit growth, a floating exchange rate, and more open capital account. Countries are significantly more likely to remove outflow controls if they have a higher income level, larger financial market, and less open capital account (likely capturing that countries with an open capital account have more limited ability to remove outflow controls). Countries with stronger legal compliance are significantly more likely to use macroprudential measures and remove controls on capital outflowswith both of these effects nonlinear and decreasing at higher levels of compliance.

It is worth highlighting two key points related to the results in Table 3. First, the estimates confirm that selection bias (with respect to relatively time invariant country characteristics as well as time-varying values of outcome variables and other policy choices) needs to be considered in an analysis of the effects of CFMs. Countries which use capital controls and macroprudential measures are different than countries which do not use these measures (based on variables such as openness, institutions, and exchange rate regimes). Variables that are intended to be influenced by capital controls and macroprudential measures (such as exchange rates and credit growth) often behave differently before adjustments in these CFMs. Second, the adjusted- $\mathrm{R}^{2}$ 's reported at the bottom of the table indicate that the equations have a moderate degree of explanatory power-but much of the variation in countries' decisions to use CFMs is not captured in the model. This is not a concern in propensity-score matching, however, and a perfect fit for the first-stage logit regression would instead be problematic. The goal of this logit model is to obtain a distribution of propensity scores in order to match treated and control observations. If the model perfectly explained countries' choices to adjust CFMs, then there would be no overlap between the propensity scores of the countries which did and did not make the policy changes, and therefore propensity-score matching would be unsuccessful.

We have also estimated several different variants of these regressions in order to assess any impact on the key results. First, we use a one-month (instead of three-month) exclusion window before and after a change in a CFM during which an observation cannot be used as a control group. This reduces the explanatory power of the regressions as expected (because countries which recently changed policies are now included as controls), but does not otherwise change the main results. Second, we repeat the basecase estimates using a cloglog specification to adjust for the fact that the distribution of the LHS variable is not normal. This has no significant effect on the results. Third, we try different combinations of the explanatory variables. For example, we avoid repetition of variables that are highly correlated (such as the TED and VIX). We also estimate each of these regressions using a stepwise regression that only includes variables which are significant at the $20 \%$ level (or less) in the first stage. These changes cause several 
variables that were not significant in the full specification to become significant with the more limited set of controls. ${ }^{20}$ These changes, however, do not significantly affect any of the key results and will be discussed in the sensitivity analysis in Section 4.3. These more parsimonious first-stage regressions also reduce the accuracy of the matching discussed below, so for our base case, we utilize the larger set of explanatory variables that are consistent across equations for the first-stage regressions.

\subsection{Matching the Treatment and Control Groups}

We next use the estimates in Table 3 to calculate propensity scores for each of the 60 countries in the sample for each week from 2009 through 2011. Then we use these propensity scores to create a control group for each treated observation (each change in a CFM) based on five matching algorithms: nearestneighbor without replacement, five-nearest neighbors with replacement, radius with caliper, kernel, and local-linear matching. ${ }^{21}$ These algorithms differ based on how many observations they include in the control set and how they weight each of these control observations. Each matching algorithm has advantages and disadvantages. Appendix C provides more information on these different techniques. In the following analysis, we begin with each of the five matching algorithms and then use different tests to evaluate their performance and select the base case(s) for the analysis. This evaluation of the different matching techniques is critical in order to ensure that they satisfy criteria required for propensity-score matching to be valid. This use of multiple matching algorithms is also useful to test the robustness of key results, as certain results can be sensitive to the creation of the control group.

Before performing these tests, however, it is useful to consider the nearest-neighbor matches for several major treatment events to form an intuitive understanding of how countries are matched. For example, in a highly publicized example of a change in a CFM, Brazil increased its tax on bond inflows from $4 \%$ to $6 \%$ on October 19, 2010. This treatment is matched with Mexico in 2010 (week 20). South Africa is a country which has been actively reducing controls on capital outflows. Its first major liberalization in the sample was in February 2009, which is matched with Malaysia (2009, week 21) and its last major liberalization in the sample was in December 2011, which is also matched with Malaysia (2011, week 50). A number of diverse countries increased their macroprudential measures, such as: Brazil (2010, week 42) which is matched with the Philippines (2010, week 42); Peru (2011, week 1) which is matched

\footnotetext{
${ }^{20}$ More specifically, in the stepwise model predicting increased controls on capital inflows, the coefficients on portfolio flows, CPI expectations, financial market size, and institutional strength become significant at the 5\% level (with the same signs). In the corresponding regressions predicting decreased controls on capital outflows, the coefficient on commodity prices becomes significant at the $5 \%$ level, and in regressions predicting increased macroprudential measures, the coefficient on the VIX becomes significant.

${ }^{21}$ See Heinrich, Maffioli, and Vázquez (2010) for an excellent discussion of the different matching methodologies and tests to ascertain if the approach is valid.
} 
with Argentina (2010, week 49); Indonesia (2011, week 4) which is matched with Turkey (2011, week 31); Korea (2010, week 1) which is matched with New Zealand (2010, week 3); and the Czech Republic (2009, week 44) which is matched with Poland (2009, week 31). These examples suggest that the nearest neighbors generally make intuitive sense in terms of the control observation sharing similar country characteristics with the treated country and occurring around the same time as the treatment event. This matching across time is facilitated by the series of controls for global variables, the "global financial cycle” in the first-stage regressions, and the substantial volatility in many of these measures over the sample period. ${ }^{22}$

In addition to these intuitive checks of nearest-neighbor matches, it is also necessary to perform more formal tests to assess if propensity-score matching is valid. The end of Appendix C discusses a number of statistics that can be analyzed to assess the bias/efficiency tradeoff. Two formal tests, however, must be satisfied: the Common Support Condition (also known as the "Overlap Test”) and Balancing Test (also known as the "Independence Assumption”).

The Common Support Condition requires that for each set of observable characteristics in $X_{i}$, there is a positive probability that a country-week observation is treated and untreated (i.e., that $0<p\left(X_{i}\right)<1$ ). Countries are "on-support” if they meet this condition. The last row for each CFM in Table A1 reports the number of countries that are on-support using each matching algorithm. All treated observations are onsupport for the nearest-neighbor, five-nearest neighbors, and local-linear matching algorithms for each of the three CFMs. The algorithm which is the least accurate in terms of yielding more "off-support" observations is the radius methodology. The radius method generates 3 countries (out of 21) that are offsupport for increased inflow controls, 1 that is off-support (out of 59) for increased macroprudential measures, and 2 (out of 29) for decreased outflow controls. ${ }^{23}$ The kernel algorithm has one treated observation that is off-support (for increased inflow controls). In the analysis that follows, we only include observations that meet this common-support condition. We also drop all observations with a propensity score higher than the maximum or lower than the minimum propensity score of the controls in order to reduce the effect of any "bad" matches. The literature suggests that this can be important, especially for radius, kernel, and local-linear matching.

\footnotetext{
${ }^{22}$ For a discussion of the importance of this global financial cycle in explaining capital flows and capital flow volatility, see Rey (2014) and Forbes and Warnock (2012).

${ }^{23}$ Observations that are off-support using the radius method are: Brazil (2009, week 47), Vietnam (2011, week 34 and 2011, week 33) for inflow controls; Ukraine (2009, week 16) for macroprudential regulations; and South Africa (2010, week 7 and 2011, week 4) for outflow controls. The observation that is off-support using the kernel method is Vietnam (2011, week 33) for inflow controls.
} 
The other key test to assess if a matching methodology is valid is the Balancing Test or "Independence Assumption”. The goal of this test is to verify that the matching was able to remove any significant differences between the treated and control groups that existed in the unmatched samples, i.e., that:

$$
\mathrm{D} \perp X \mid p(X)
$$

Table 4 reports results of this test for increased controls on capital inflows. It begins by showing mean values for the treated group $\left(\mu_{T}\right)$ and control group $\left(\mu_{C}\right)$ for the unmatched sample for each of the variables in the vector $X$ used to estimate propensity scores. The table also reports $t$-statistics for tests of the hypothesis that the mean of each variable in the treated group is equal to the mean in the control group ( $H 0: \mu_{T}=\mu_{C}$ ). There are significant differences between the treated and the unmatched control group for seven variables. Countries were significantly more likely to increase their controls on capital inflows if they had greater real exchange rate appreciation, higher expected inflation, less open capital accounts, less developed financial markets, lower income per capita, and lower levels of legal compliance (including the level and squared terms). These significant differences across the treated and unmatched control groups highlight that selection bias is important; countries which chose to increase their controls on capital inflows had significantly different characteristics than countries which did not adjust their controls.

The right side of Table 4, however, indicates that each of the matching algorithms except the kernel methodology is able to remove this selection bias. The columns show mean values for each of the variables in $X$ in the matched control groups using all five matching algorithms. It also reports the same $t$ statistics of tests for significant differences between the treated and matched control groups for each of the variables. In each of these tests, there are no longer significant differences between the treated and control groups for the nearest-neighbor, five-nearest neighbor, radius, and local-linear matching algorithms. Each of these four algorithms has successfully removed the significant differences across groups as measured by the variables in the vector $X$. In contrast, after using the kernel algorithm, there are still significant differences between the treated and matched control groups based on five variables.

Results of this balancing test are similar for increases in macroprudential measures and decreases in controls on capital outflows. In each case, there are significant differences in the means of several variables between the treated and unmatched control groups, but after using each of the matching algorithms except the kernel methodology, there are no longer any significant differences. For example, in the model predicting increases in macroprudential measures, there are significant differences between the treated and unmatched control group for nine variables: credit growth, expected inflation, the VIX, 
commodity prices, the exchange rate dummy, GDP per capita, financial market size, legal compliance, and legal compliance squared. After using all four matching methodologies except the kernel algorithm, there are no longer any significant differences between the treated and matched control groups. After using the kernel algorithm, there are still significant differences between the treated and matched control groups according to one variable in $X$ at the $5 \%$ significance level and five variables at the $10 \%$ significance level. Therefore, all matching algorithms successfully meet the key test for balancing except for the kernel technique.

Based on this series of statistics and tests, and in order to simplify the discussion that follows and keep the number of reported results manageable, we will focus on results obtained using the local-linear matching algorithm as the "base case" and also show key results using five-nearest neighbors. We do not focus on kernel matching as it does not remove all significant differences between the treated and matched control groups. We do not focus on radius matching as it yields the greatest number of observations that are off-support. Of the three remaining methodologies, local-linear has the advantage of producing a mean propensity score for the matched sample that is the closest to that for the treated group for changes in controls on inflows and outflows. Local-linear matching also has the theoretical advantage that it uses all available information. Five-nearest neighbor matching also performs well, especially in terms of yielding low mean absolute bias (as shown in Table A1). For each significant result, however, we will discuss whether the finding is robust to all of the matching algorithms.

\section{Impact of Capital Controls and Macroprudential Measures}

In order to test for the impact of changes in capital controls and macroprudential measures, we compare outcome variables for when countries used these policies (the treated observations) with their matched control groups, using the matching algorithms developed in the last section. We focus on outcome variables that are frequently cited as reasons for adjusting CFMs: the exchange rate, portfolio flows, other macroeconomic variables (interest rate differentials, equity markets, and inflation), financial market volatility (in the exchange rate, portfolio flows, and interest rates) and other financial fragilities (bank leverage, private credit growth, bank credit growth, inflation expectations, and exposure to short-term debt, portfolio liabilities, and foreign-currency liabilities). ${ }^{24}$

\footnotetext{
${ }^{24}$ In most cases, we estimate how changes in CFMs affect the growth rate of these outcome variables. In several cases (such as for the effect on interest-rate differentials), we estimate the effect on the change in the outcome variable. The text and figures indicate how each outcome variable is measured.
} 
To test for any significant effect of CFMs on these variables, we calculate the average treatment effect on the treated (ATT) for each CFM on each outcome variable. The ATT is calculated by comparing the average value of the outcome variable for treated observations with the average value for the respective matched control observations. For our base case using local-linear matching, the average is calculated using higher weights for control observations closer to the treated observation, based on the assigned weights resulting from the nonparametric estimation. Since the propensity scores are estimated, it is necessary to bootstrap the standard errors for the ATT in order to evaluate if there is a significant difference between the treated and control groups. ${ }^{25}$

We test for effects on outcome variables at any week over the six-month window after the treatment in order to capture any immediate as well as lagged effects of CFMs. We do not focus on longer-term effects as the matching algorithms (which incorporate changes in the global environment) are less accurate over longer time periods. In order to estimate effects over this 6-month window, we calculate a cumulative ATT for each of the 26 weeks after the policy change. For example, to estimate the ATT of increased controls on capital inflows on the nominal exchange rate, we calculate the average percent change in the exchange rate for the treated and control groups. For the first treatment period, this would be the change from period 0 (the treatment date when the controls were increased) to period 1 ( 1 week later). For the second post-treatment period, this would be the percent change from period 0 to period 2 (2 weeks). For the twentieth period, this would be the percent change from period 0 to period 20 ( 20 weeks). One benefit of this approach is that it allows us to capture any effects of CFMs over different time periods, rather than choosing, a priori, the time period on which to focus. One disadvantage of this approach is that it does not incorporate any adjustment for post-treatment covariates. Finally, we also winsorize all outcome variables at the $1 \%$ level in order to avoid having results driven by extreme outliers.

\subsection{Results: Base Case}

The most straightforward way to characterize the effects of CFMs over the different weekly windows over 6 months is graphs of the ATTs for each type of CFM and outcome variable. Figure 2 presents results for key variables targeted by capital controls and macroprudential measures—-the exchange rate (nominal and real) and net portfolio inflows. Figure 2a uses local-linear matching and Figure 2b uses fivenearest neighbors. Each bar shows the magnitude of the estimated ATT for the accumulated time in weeks since the change in the CFM occurred (the treatment). Dark black shading in a bar indicates that the ATT for that week is significant at the $5 \%$ level, and medium-blue shading indicates significance at the $10 \%$ level. The black line is the fitted line for the average treatment effect.

\footnotetext{
${ }^{25}$ See Lechner (2002) for the appropriate methodology. We use 100 repetitions for the bootstrap.
} 
The top two graphs in Figures 2a and 2b show that increased controls on capital inflows have no consistently significant effects on the real or nominal exchange rates relative to that for the control groups. The results based on local-linear matching (in Figure 2a) indicate that increasing controls on inflows may lead to a small real deprecation of less than $0.5 \%$ over the first two months, increasing gradually to reach a maximum real deprecation of $2 \%$ at about five months. This effect, however, is only significant at the $5 \%$ level for three weeks in the six-month window. Moreover, the results based on fivenearest neighbor matching in Figure $2 b$ indicate that any effect on the nominal or real exchange rate is insignificant and small (peaking at a 1.5\% real depreciation). These effects—even if they were significant-are very small relative to the normal volatility in exchange rates. Other matching methods also yield no consistent estimates. ${ }^{26}$ These results suggest that increased controls on capital inflows do not have a significant or economically important effect on a country's exchange rate.

The second rows in Figures 2a and $2 \mathrm{~b}$ show the ATT from reducing controls on capital outflows. In this case, the effect is estimated to always be negative (a depreciation), and the magnitude is slightly larger. More specifically, removing controls on capital outflows causes a depreciation of the nominal and real exchange rate (relative to the counterfactual) which grows over time and peaks at about $2 \%$ after four months. This effect is more often significant-in the majority of weeks using local-linear matching and at the $10 \%$ level for over a month using five-nearest neighbor matching. Results based on radius matching are very similar to those based on local-linear matching (with slightly larger estimated effects). The bottom rows of Figures 2a and 2b show the impact of increased macroprudential measures. The estimated effects are even smaller and generally insignificant; even the direction of any effects on the nominal exchange rate varies based on the matching method. The impact of increased macroprudential measures on the real exchange rate appears to be negative (albeit usually insignificant)—which is in contrast to the OLS results which did not correct for selection bias and generally found a positive effect of macroprudential regulations on the real exchange rate (as discussed in Section 3.1).

The graphs in the right column of Figures 2a and 2b show the effects of different CFMs on net portfolio inflows. ${ }^{27}$ They indicate that increased controls on capital inflows cause net portfolio inflows to decline over time, with the effect gradually increasing to a maximum 3\% decline in net inflows (relative to the

\footnotetext{
${ }^{26}$ For example, nearest-neighbor matching indicates that increased inflow controls cause a small appreciation of the nominal and real exchange rates, while radius matching indicates a small depreciation, with estimated effects insignificant in most weeks.

${ }^{27}$ Net portfolio inflows are calculated as cumulative flows over the last quarter (13 weeks) and expressed as a percent of lagged total portfolio assets. Results are similar if portfolio inflows are not expressed as a percent of portfolio assets.
} 
counterfactual) after about 5 months based on local-linear matching. This effect is significant at the 5\% level for several weeks, but smaller and always insignificant (at the 5\% level) based on five-nearest neighbor and radius matching (and in most weeks based on the other techniques). Decreased controls on capital outflows and increased macroprudential measures also generate declines in net capital inflows over time, but these effects are even smaller in magnitude and insignificant in every week with any of the five matching algorithms.

Next, Figure 3 graphs the ATT for macroeconomic variables that are also mentioned as targets for CFMs, albeit usually of secondary importance relative to exchange rates and portfolio flows. We estimate the effects on countries' interest-rate differentials versus the United States (using rates on 3-month Treasury bills), equity indices, and CPI inflation (not shown). We report results using local-linear matching (and results using five-nearest neighbor matching are similar). Increasing controls on capital inflows does not have a significant effect on any of the macroeconomic variables in any week. Decreasing controls on capital outflows and increasing macroprudential measures may reduce a country's interest rate differential relative to the United States, but the effect is small and only significant for less than four weeks (including using other matching algorithms). The effect of changes in capital controls and macroprudential measures on equity indices and inflation are insignificant at the $5 \%$ level in every week, and usually even at the $10 \%$ level. Therefore, there is little evidence that any of the CFMs can significantly affect equity returns or inflation. Reduced controls on outflows and increased prudential measures may have small effects on interest-rate differentials, but only for a short period.

We have also evaluated the effect of CFMs on the volatility of key variables. Volatility is measured as the standard deviation over the previous 26 weeks and we estimate the volatility in the nominal exchange rate, net portfolio inflows, and interest-rate differentials (based on overnight rates), all defined in Appendix B. Increased controls on inflows are more likely to reduce volatility, and decreased controls on outflows are more likely to increase volatility. Macroprudential measures are estimated to decrease exchange rate volatility, but increase capital flow volatility—a result which is shown in the right-hand column of Figure 3. Once again, however, all of these estimated effects are insignificant or short-livedexcept for the positive effect of increased macroprudential measures on portfolio-flow volatility after 3 months (which is consistently significant across matching methodologies). Therefore, there is little evidence that adjusting capital controls or increasing macroprudential measures can significantly reduce the volatility of key financial variables, and increasing macroprudential measures may instead increase the volatility in portfolio flows. 
Finally, one goal of capital controls, and especially macroprudential measures, which has recently received more attention is to reduce financial vulnerability. Data measuring financial vulnerabilities for our diverse sample is limited, so we focus on several available measures that capture different forms of potential vulnerability and that are frequently included in early-warning models: the growth in private credit (relative to GDP), the growth in bank credit (relative to GDP), inflation expectations, bank leverage (measured as bank credit to deposits), and exposure to short-term external debt (relative to GDP), portfolio liabilities (as a share of total liabilities), and foreign-currency liabilities (as a share of total liabilities). Since these outcome variables are reported at a lower frequency than the variables analyzed above, we estimate ATTs for the corresponding time period available for each outcome variable (as specified in Appendix B) for a longer window of 52 weeks. For example, information on the growth in private credit is available on a monthly basis, so we estimate cumulative ATTs for each month over a year, and data on bank leverage is only available at an annual basis, so we estimate the ATT for one year only.

To simplify the discussion of this large number of results, Figure 4 shows all results when increased inflow controls, decreased outflow controls, or increased macroprudential measures have a significant effect (at the 5\% level) on a measure of financial vulnerability for both local-linear and five-nearest neighbor matching for at least a week. Increased macroprudential measures significantly reduce expected inflation, reduce bank leverage ${ }^{28}$, reduce bank credit growth, and initially reduce the portfolio share of liabilities (although this final effect reverses after a year). Increased controls on capital inflows significantly reduce private credit growth (although this affect fades and becomes insignificant after 34 weeks). Moreover, the magnitude of some of these effects can be economically important. For example, an increase in macroprudential regulations is correlated with a decline in expected inflation of about $0.4 \%$ after six months relative to the counterfactual. This series of results indicates that CFMs appear to be most effective in reducing different measures of financial vulnerability. Macroprudential measures appear to be especially potent as they show evidence of being able to significantly reduce inflation expectations, bank leverage, bank credit growth, and exposure to portfolio liabilities in the short term.

\subsection{Results: More Narrowly Defined CFMs}

The measures of capital controls and macroprudential measures used in the previous section are defined broadly and encompass very different types of policies that may have different goals. Different types of capital controls and macroprudential measures may be more effective at targeting certain variables. Therefore, this section repeats the main analysis using narrower definitions of capital controls and

\footnotetext{
${ }^{28}$ Data on bank leverage is extremely limited, however, so these results should be interpreted with caution.
} 
macroprudential measures. More specifically, we test for effects of capital controls on equities or bonds, of “major” controls (that received more attention by financial analysts), and of macroprudential regulations directed at banks' international exposure or foreign exchange.

To begin, we more narrowly classify the capital controls in our database as targeting bond flows, equity flows, and/or FDI (with some events targeting more than one type of flow). Of the 63 events that involve increased inflow controls or decreased outflow controls, more events target bonds (45 events) and equities (33 events) compared to FDI (only 13 events). Then we estimate the effect of changes in controls targeting bonds or targeting equities on exchange rates (nominal and real), net portfolio inflows, net bond inflows, and net equity inflows. There are no consistently significant effects on real or nominal exchange rates, net portfolio inflows, or net bond inflows from changes in equity or bond controls. The only result that is significant is that lifting controls on equity and/or bond flows can lead to a significant reduction in net equity inflows. ${ }^{29}$ This may indicate that controls on capital inflows are more effective at reducing equity than bond flows, but it is impossible to draw strong conclusions for two reasons. First, there is substantial overlap in the events when countries change controls on equities and bonds, making it impossible to isolate the effect of changes in just one type of control that does not occur simultaneously with the other. ${ }^{30}$ Second, the data on bond flows is less comprehensive than the data on equity flows, which makes comparing estimates for the different types of flows imprecise. ${ }^{31}$

Next, we more narrowly define the capital controls and macroprudential measures in our database as CFMs that were "major" in the sense that they received more discussion or attention by investors, financial analysts, or international financial institutions. CFMs that receive more widespread attention may have greater effects if CFMs work at least partially through a signaling effect (as suggested in Forbes et al., 2012)—although it is also possible that larger changes in CFMs generate more attention and therefore have a larger effect due to the size of the change rather than the signal. Since our database is not

\footnotetext{
${ }^{29}$ This result is consistent with Forbes et al. (2012), which finds that changes in Brazil's taxes on bond inflows generated a significant reduction in equity allocations to Brazil. This result is also consistent with a key argument in Bartolini and Drazen (1997), which models how changes in capital controls can affect capital flows not directly affected by the policy change when investors have imperfect information. Although Bartolini and Drazen (1997) focuses on an example in which the signal from removing controls on capital outflows leads to a larger net capital inflow and currency appreciation (which is the opposite effect found in this paper), the relevant insight for our analysis is that a change in policy can be interpreted as providing a signal about future government policy toward capital mobility in general.

${ }^{30}$ There are several events in which there are changes in controls on bond flows that do not occur simultaneously with changes in controls on equity flows, but the sample size is too small to use propensity-score matching with any degree of confidence. There are very few events in which there are changes in controls on equity flows that do not occur simultaneously with changes in controls on bond flows.

${ }^{31}$ See Forbes et al. (2012) for information on coverage in the EPFR database on equity and bond flows.
} 
able to capture the magnitude or intensity of different types of CFMs, this extension can also be loosely interpreted as an assessment if larger changes in CFMs had different effects than in the full sample.

To create this definition of major controls, we review a broad sample of analyst reports written from 2009-2012 on CFMs, as well as papers written by the IMF and think tanks that surveyed recent changes in CFMs over this time period. ${ }^{32}$ Any CFM event that is mentioned in at least one of these sources is then defined as a major event. Only 39 events in the full database of 135 CFMs aimed at reducing inflow pressures are identified as major events, confirming that many of the changes in CFMs may have been fairly minor changes or occurred in smaller countries that did not receive substantial attention by investors.

Then we repeat the base-case estimation, but only include these major CFM events. Most of the estimated ATTs are similar to the key results reported above for the larger sample. The only noteworthy exceptions are reported in Figure 5. The top row shows the effects of major increases in inflow controls and the second row shows the effects of major decreases in outflow controls. These major changes in capital controls have larger and consistently significant negative effects on net portfolio inflows than found for the larger sample, but mixed robustness across matching methods. The middle column also indicates that the reduction in net portfolio flows from major changes in controls may come at a cost. Major changes generate increased volatility in capital inflows — and this effect is significant, robust, and much larger for increased inflow controls. It is also worth noting that removing major outflow controls causes a significant deprecation of the real exchange rate for several weeks, but major increases in inflow controls does not have a similar effect. This supports the prior evidence from the larger sample of events that removing controls on capital outflows is more likely to cause a depreciation of the real exchange rate (relative to the counterfactual) than increasing controls on inflows.

As a final extension of the base analysis, we classify the changes in macroprudential measures in our database as measures targeting banks' international exposures and those targeting foreign exchange exposures. This classification shows that of the 72 increases in macroprudential measures in the sample, 57 were aimed directly at banks and 63 aimed directly at foreign exchange exposures. There are a substantial number of measures which simultaneously involve restrictions in multiple areas, such as limits on the foreign exchange exposure of banks, which makes it impossible to isolate the effects of just one

\footnotetext{
${ }^{32}$ We use analyst reports written by Goldman Sachs, HSBC, JPMorgan, and Morgan Stanley. We also review regular reports on capital flows written by the Institute of International Finance, Peterson Institute for International Economics, and a series of reports on CFMs written by the IMF.
} 
type of change in these macroprudential regulations. With this caveat, we test if these narrower types of macroprudential measures have different effects on key outcome variables than found for the broader sample of treatments. The key results reported above generally do not change significantly. The only noteworthy differences are that increased regulations targeting banks tend to more often have significant negative effects on private credit growth and exposure to short-term debt than regulations targeting foreign exchange—although robustness varies across matching methodologies.

\subsection{Results: Additional Sensitivity Tests}

In addition to the robustness tests reported above, we also perform a series of sensitivity tests to assess if the key results are driven by the specification of the first-stage regressions used to calculate the propensity scores, the definition of the exclusion window, or any key countries which make frequent changes to their CFMs. First, we test if different specifications for the first-stage logit model used to calculate propensity scores affect key results. We have included additional variables in the model (such as the current account balance relative to GDP, budget balance relative to GDP, and debt to GDP); these additional variables are never significant and do not affect key results (except including debt ratios shrinks the sample size due to limited data availability). We have also estimated more parsimonious specifications for the first-stage regressions. For example, given the large number of insignificant and multicollinear variables in the first stage, we use a stepped regression and only include variables which are significant at the $20 \%$ level in the logit regressions reported in Table 3. As expected, this causes the variables remaining in the regression to more often be significant. The main results on the effects of changes in CFMs on key outcome variables, however, are not only unchanged, but basically identical to the results discussed above. This confirms that the key results do not appear to be highly sensitivity to modifications in the first-stage regressions used to calculate propensity scores. This also confirms one of the important advantages of propensity-score matching over OLS in terms of its flexibility to the inclusion of large numbers of observable variables in the first-stage model.

Second, we test for any impact of adjusting the length of the exclusion window-the length of time before and after a country changes a CFM during which it is not included as a treated or control observation. In our base case, we define the exclusion window to last for three months. We also repeat the main analysis using a shorter exclusion window of one month. As expected, this increases the sample size but also decreases the adjusted- $\mathrm{R}^{2}$ for the first-stage logit regressions. ${ }^{33}$ The main results on the effects of changes in CFMs on key outcome variables, however, are unchanged. The only noteworthy change is that the

\footnotetext{
${ }^{33}$ For example, in the first-stage logit regression predicting increased controls on capital inflows, the sample size increases to 5167 (from 4953 in the base case) and the adjusted- $\mathrm{R}^{2}$ falls to 0.170 (from 0.192 in the base case).
} 
effect of removing controls on capital outflows on the real exchange rate is weaker under several matching algorithms than in the base case. We have also attempted to repeat the analysis using a longer exclusion window of six months, but this significantly reduces the sample size of treated observations and makes the propensity score matching less effective.

Finally, there are several countries in the sample which make frequent changes to their capital controls and macroprudential measures, and could therefore be driving key results. Countries which frequently change their CFMs may also have different effects on key outcome variables. Changes could have a greater effect because the country already has enforcement mechanisms in place to ensure the new rules are applied. Or changes could have a smaller effect because investors expect frequent changes and are less surprised and likely to adjust their behavior in response to these changes. Table 1 shows that Peru stands out as increasing macroprudential measures most often (with 14 changes), Brazil for increasing controls on capital inflows (7 changes), and South Africa for decreasing controls on capital outflows (8 changes). To see if these countries which more often adjusted their CFMs affect the key results, we repeat the main estimation as in the base case, but exclude these three countries from the relevant sample.

The key results discussed above are unchanged, with two exceptions. First, when Brazil's increases in inflow controls are excluded from the sample, this reduces any estimated effects of controls on net capital inflows (which were only significant for selected weeks and certain matching methods in the base case). This also renders the effect of controls on equity inflows (discussed in Section 4.2) insignificant for every single week. Therefore, Brazil's use of capital controls appears to have had stronger effects on capital flows - and especially equity flows - than for the other countries in the sample. ${ }^{34}$ Second, when South Africa's reductions in outflow controls are excluded from the sample, the effect of outflow controls on the real exchange rate is larger and more often significant, and the effect on the nominal exchange rate is now significant. Therefore, removing controls on capital outflows appears to have a stronger effect on the exchange rate for most countries than occurred for South Africa.

\subsection{Results: Tying it All Together}

The results in this section indicate that CFMs can have significant effects on some of the variables which they are intended to influence, but in most cases the effects are insignificant, short-lived, small in magnitude, and not robust across different matching methodologies. The strongest effects of CFMs

\footnotetext{
${ }^{34}$ Forbes et al. (2012) provide a discussion of why this could occur; Brazil's adjustments to controls on capital inflows from 2008 through 2011 were the most high-profile examples of the newly popular approach to the use of CFMs. This is also an emerging market with a large market capitalization and that was fairly open to foreign investment, therefore potentially generating a stronger reaction by investors than would occur in other markets.
} 
appear to be in reducing certain measures of financial vulnerability. Increases in macroprudential measures related to international transactions significantly reduce bank leverage, inflation expectations, and bank credit growth over the following year. Increases in these macroprudential regulations reduce exposure to portfolio liabilities over a quarter and increases in controls on capital inflows reduce private credit growth over about eight months—although these last two effects reverse by the end of a year.

In contrast to these robust results showing that CFMs can reduce financial fragilities, there is little consistent evidence that they can affect two other primary goals: exchange rate appreciation and net capital inflows. Removing controls on capital outflows causes a depreciation of the real exchange rate which peaks at just over $2 \%$ after about four months. This result is significant for more weeks and stronger across different matching methodologies when South Africa's frequent changes in outflow controls are dropped from the sample. Increased capital inflow controls and macroprudential measures have even smaller and generally insignificant effects on exchange rates (nominal and real) and capital flows. “Major” changes in capital controls (and especially Brazil’s adjustments to inflow controls) which received more attention from investors have stronger effects on portfolio inflows, although major increases in inflow controls also cause a significant increase in capital flow volatility and translate into little consistent, significant, or economically meaningful impact on the real exchange rate.

Finally, the results show little evidence that changes in CFMs affect other macroeconomic and financial market variables over the short- and medium-term. Increased inflow controls and decreased outflow controls have no significant effect on equity indices, inflation, interest-rate differentials versus the United States, or the volatility of exchange rates, portfolio flows, or interest-rate differentials. Increased macroprudential regulations related to international exposures also generally have no consistently significant effect on any of these variables, except that they can reduce interest-rate differentials for short periods of time by a small amount and may actually increase - instead of decrease — portfolio flow volatility. Any indirect effects of CFMs on these macroeconomic and volatility measures due to any benefits from reduced financial vulnerability, however, would not be captured if they occurred over longer time periods than measured in this analysis.

\section{Conclusions}

An extensive literature has attempted to assess the impact of capital controls and, to a lesser extent, macroprudential measures. Challenges for this literature include selection bias and data availability. Countries which change their capital controls and macroprudential measures are different than countries 
which do not. Countries adjust these policies in response to changes in key macroeconomic variables, variables which are often the targets of the controls and macroprudential measures. This paper shows that these challenges are not just hypothetical and should be considered when estimating the effect of CFMs. In order to do so, it uses a propensity-score methodology. This technique uses several matching algorithms to create control groups establishing the counterfactual for key outcome variables in the absence of changes in CFMs. This is the first attempt (to the best of our knowledge) to use this methodology to analyze the impact of capital controls and macroprudential measures.

In order to perform this analysis, it is necessary to construct a new database which includes detailed information at a higher frequency and for a larger sample of countries on changes in capital controls and macroprudential measures. We only focus on the subset of macroprudential measures classified as “capital-flow management measures”, i.e., related to foreign exposures or foreign transactions, and do not include purely domestic macroprudential regulations. The dataset includes weekly information for 60 economies from 2009 through 2011. It is unique in that it is the first dataset that captures changes in CFMs not only for a large set of countries, but also at a high frequency. We estimate propensity scores of the probability that each country adopts a specific capital control or macroprudential measure in each week based on a set of domestic and global variables. The analysis then uses these propensity scores to match each policy change (i.e., treatment) with a control group in order to create a counterfactual against which to assess the effect of the policy change on key outcome variables. The analysis focuses on the impact of CFMs aimed at reducing pressures from capital inflows and currency appreciation-increased controls on capital inflows, decreased controls on capital outflows, and increased macroprudential regulations.

The results indicate that certain CFMs can accomplish specific goals-especially in terms of reducing financial vulnerabilities — but most CFMs are ineffective at accomplishing other stated goals. More specifically, macroprudential measures related to international exposures can significantly improve measures linked to financial fragility, such as bank leverage, inflation expectations, bank credit growth, and exposure to portfolio liabilities. Increased controls on capital inflows can reduce private credit growth (although this effect, as well as that for portfolio liabilities, appears to fade and reverse after six months). CFMs, however, do not appear to have a significant effect on most other macroeconomic variables and financial market volatilities over the short and medium-term, including on equity indices, inflation, interest-rate differentials, or the volatility of exchange rates, portfolio flows, or interest-rate differentials. CFMs have limited effectiveness achieving two of their primary goals: reducing exchange rate appreciation and net capital inflows. One type of CFM—removing controls on capital outflows—can 
yield a significant but small depreciation of the real exchange rate (with a maximum depreciation of less than $2.5 \%$ over four months relative to the counterfactual). "Major" changes in capital controls which received more attention from investors are more likely to affect portfolio inflows, although major changes in inflow controls can also cause a significant increase in capital flow volatility and translate into no consistent, significant, or economically meaningful impact on the real exchange rate.

These results should be interpreted with several cautions. The analysis only captures any immediate and medium-term effects, and not longer-term effects that occur after six months (or in some cases, one year). The analysis does not capture any costs related to the policies that are not included in the set of outcome variables (such as costs related to financial intermediation, enforcing the regulations, reduced access to credit for certain groups, or distortions from attempts to evade the measures). ${ }^{35}$ These costs should be weighed against any benefits before implementing any of these policies. Also, the estimated ineffectiveness of many capital-flow management measures may reflect challenges in calibrating, timing, communicating, and enforcing the policies. If any such shortcomings were addressed, especially as policymakers have more experience using these tools, it is possible that capital controls and macroprudential measures could be used more effectively in the future.

Subject to these caveats, the series of results in the paper has two important implications. First, much of the recent policy debate on the use of CFMs to reduce exchange rate appreciation has focused on the use of controls on capital inflows. This paper finds little evidence that controls on capital inflows can accomplish this goal in a systematic manner. Instead the evidence suggests that removing controls on capital outflows (if present) tends to be more effective for limiting exchange rate appreciation. This supports the recent focus in papers such as Aizenman and Pasricha (2013) and Bayoumi and Ohnsorge (2013) on the importance of the liberalization of capital outflows by domestics rather than just capital inflows from foreigners. The analysis in this paper, however, only focuses on the removal of existing controls on capital outflows that have generally been in place for an extended period. Removing capital controls that were put into place to limit capital outflows during a severe crisis (such as in Iceland in 2008 or Cyprus in 2013) could involve additional complexities that are not analyzed in this paper. ${ }^{36}$

Finally, the debate on capital controls (and to a lesser extent macroprudential measures) has historically focused on their impact on exchange rates, capital flows, and other macroeconomic variables. Only

\footnotetext{
${ }^{35}$ For evidence on the costs of capital controls, see Forbes (2007a, 2007b). For evidence on the costs and potential spillover effects of capital controls and macroprudential policies, see Beirne and Friedrich (2013) and Jeanne (2013).

${ }^{36}$ For a discussion of these risks in removing Iceland's capital controls, see Baldursson and Portes (2013).
} 
recently has the debate shifted to using these policies to reduce other forms of financial vulnerability (i.e., Ostry et al., 2012 and He, 2013). The evidence in this paper suggests that this new focus is likely to be more effective. Capital controls and macroprudential measures have few significant effects on exchange rates, capital flows, and other macroeconomic variables over the short- and medium-term. In contrast, macroprudential measures related to international exposures (and to a lesser extent capital controls) appear to be more effective at reducing other forms of financial fragility.

Although limited, this impact of CFMs can still be important. ${ }^{37}$ Even if macroprudential measures can not directly affect prices or other key macroeconomic variables, they could stabilize economies by reducing financial vulnerabilities and therefore improving other macroeconomic measures over time. Policymakers evaluating whether to use different forms of capital controls and macroprudential measures should therefore be realistic about what these measures are (and are not) good for.

\footnotetext{
${ }^{37}$ This agrees with evidence from Hong's Kong's use of macroprudential measures to reduce vulnerability to the housing sector. He (2103) discusses how the Hong Kong Monetary Authority implemented macroprudential measures targeting the property market. These measures did not significantly reduce property-price growth or property transactions, but did reduce financial fragilities related to exposure to the housing sector — such as banking and household leverage related to housing. This made the economy more resilient during the Global Financial Crisis.
} 


\section{References}

Aizenman, J., Pasricha, G., 2013. Why Do Emerging Markets Liberalize Capital Outflow Controls? Fiscal Versus Net Capital Flow Concerns. Journal of International Money and Finance 39 (December): 28-64.

Angrist, J., Hahn, J., 2004. When to Control for Covariates? Panel Asymptotics for Estimates of Treatment Effects. Review of Economics and Statistics 86 (1): 58-72.

Angrist, J., Jordà, O., Kuersteiner, G., 2013. Semiparametric Estimates of Monetary Policy Effects: String Theory Revisited. NBER Working Paper 19355.

Angrist, J., Kuersteiner, G., 2011. Casual Effects of Monetary Shocks: Semiparametric Conditional Independence Tests with a Multinomial Propensity Score. Review of Economics and Statistics 93(3): 725-747.

Angrist, J., Pischke, J.-S., 2008. Mostly Harmless Econometrics: An Empiricist’s Companion. Princeton: Princeton University Press.

Baldursson, F., Portes, R., 2013. Capital Controls and the Resolution of Failed Cross-Border Banks: The Case of Iceland. CEPR Discussion Paper No. 9706.

Bartolini, L., Drazen, A., 1997. Capital-Account Liberalization as a Signal. American Economic Review 87(1): 138-154.

Bayoumi, T., Ohnsorge, F., 2013. Do Inflows or Outflows Dominate? Global Implications of Capital Account Liberalization in China. IMF Working Paper WP/13/189.

Beirne, J., Friedrich, C., 2013. Capital Flows and Macroprudential Policies-A Multilateral Assessment of Effectiveness and Risks. Unpublished mimeo.

Blanchard, O., Dell’Ariccia, G., Mauro, P., 2013. Rethinking Macro Policy II: Getting Granular. IMF Staff Discussion Note SDN/13/03.

Bluedorn, J., Duttagupta, G., Guajardo, J., Topalova, P., 2013. Capital Flows Are Fickle: Anytime, Anywhere. IMF Working Paper WP/13/183.

Chamon, M., Garcia, M., 2013. Capital Controls in Brazil: Effective? PUC-Rio Working Paper No. 606.

Chari, A., Chen, W., Dominguez, K., 2011. Foreign Ownership and Firm Performance: Emerging Market Acquisitions in the United States. Mimeo.

Chinn, M., Ito, H., 2008. A New Measure of Financial Openness. Journal of Comparative Policy Analysis 10(3): 309-322. Dataset updated as of 04/24/2103. Available at: http://web.pdx.edu/ ito/ChinnIto_website.htm.

Cline, W., 2010. Financial Globalization, Economic Growth, and the Crisis of 2007-09. Peterson Institute of International Economics: Washington, DC. 
Costinot, A., Lorenzoni, G., Werning, I., 2011. A Theory of Capital Controls as Dynamic Terms-of-Trade Manipulation. NBER Working Paper 17680.

Das, K., Bergstrom, K., 2012. Capital Account Liberalization, Selection Bias, and Growth. Mimeo.

Dehejia, R., Wahba, S., 2002. Propensity-Score Matching Methods for Nonexperimental Causal Studies. Review of Economics and Statistics 84(1):151-161.

Ehrmann, M., Fratzscher, M., 2006. Global Financial Transmission of Monetary Policy Shocks. European Central Bank Working Paper Series No. 616 (April).

Fan, J., 1992. Design-Adaptive Nonparametric Regression. Journal of the American Statistical Association, 87 (420): 998-1004.

Fan, J., 1993. Local Linear Regression Smoothers and their Minimax Efficiencies. The Annals of Statistics, 21(1): 196-216.

Forbes, K., 2007a. The Microeconomic Evidence on Capital Controls: No Free Lunch, in Edwards, S. (Ed.), Capital Controls and Capital Flows in Emerging Economies: Policies, Practices, and Consequences. Chicago: University of Chicago Press, 171-202.

Forbes, K., 2007b. One Cost of the Chilean Capital Controls: Increased Financial Constraints for Smaller Traded Firms. Journal of International Economics 71(2): 294-323.

Forbes, K., Fratzscher, M., Kostka, T., Straub, R., 2012. Bubble Thy Neighbor: Portfolio Effects and Externalities of Capital Controls. NBER Working Paper 18052.

Forbes, K., Klein, M., 2013. Pick Your Poison: The Choices and Consequences of Policy Responses to Crises. MIT Sloan Working Paper 5062-13.

Forbes, K., Warnock, F., 2012. Capital Flow Waves: Surges, Stops, Flight and Retrenchment. Journal of International Economics 88(2): 235-251.

Fratzscher, M., 2012. Capital Controls and Foreign Exchange Policy. CEPR Discussion Paper No. DP8788.

Fratzscher, M., Lo Duca, M., Straub, R., 2012. Quantitative Easing, Portfolio Choice, and International Capital Flows. Mimeo.

Ghosh, A., Qureshi, M., Tsangarides, C., 2011. Words vs. Deeds: What Really Matters? IMF Working Paper WP/11/112.

Glick, R., Guo, X., Hutchison, M., 2006. Currency Crises, Capital-Account Liberalization, and Selection Bias. Review of Economics and Statistics 88(4): 698-714.

Habermeier, K., Kokenyne, A., Baba, C., 2011. The Effectiveness of Capital Controls and Prudential Policies in Managing Large Inflows. IMF Staff Discussion Note SDN/11/14.

He, D., 2013. Hong Kong’s Approach to Financial Stability. International Journal of Central Banking 9 (1, March): 299-313. 
Heckman, J. J., Ichimura, H., Todd, P., 1998. Matching as an Econometric Evaluation Estimator. Review of Economic Studies 65(2): 261-294.

Heckman, J. J., Ichimura, H., Todd, P., 1997. Matching As An Econometric Evaluation Estimator: Evidence from Evaluating a Job Training Programme. Review of Economic Studies 64 (221): 605-654.

Heinrich, C., Maffioli, A., Vázquez, G., 2010. A Primer for Applying Propensity-Score Matching. InterAmerican Development Bank, Technical notes No. IDB-TN-161.

International Monetary Fund, (various years). Annual Report on Exchange Arrangements and Exchange Restrictions. Washington, DC. Years 2010-2012.

International Monetary Fund, 2012. The Liberalization and Management of Capital Flows: An Institutional View (Nov. 14).

International Monetary Fund, 2011a. Recent Experiences in Managing Capital Inflows-Cross-Cutting Themes and Possible Policy Framework. Paper prepared for IMF Board, February 14.

International Monetary Fund, 2011b. The Multilateral Aspects of Policies Affecting Capital Flows. Paper prepared for the IMF Board, October 13.

Jeanne, O., 2013. Macroprudential Policies in a Global Perspective. Paper prepared for 2013 Asia Economic Policy Conference, Federal Reserve Bank of San Francisco, Nov. 3-5, 2013. Available at: http://www.frbsf.org/economic-research/events/2013/november/asia-economic-policyconference/program/files/Macroprudential-Policies-in-a-Global-Perspective.pdf

Jeanne, O., 2012. Who Needs to Open the Capital Account? Mimeo. Peterson Institute of International Economics.

Jeanne, O., Korinek, A., 2010. Managing Credit Booms and Busts: A Pigouvian Taxation Approach. NBER Working Paper 16377.

Jinjarak, Y., Noy, I., Zheng, H., 2013. Capital Controls in Brazil-Stemming a Tide with a Signal? Journal of Banking and Finance 37(8): 2938-2952.

Jordà, Ò., Taylor, A., 2013. The Time for Austerity: Estimating the Average Treatment Effect on Fiscal Policy. NBER Working Paper 19414.

Klein, M., 2012. Capital Controls: Gates versus Walls. Brookings Papers on Economic Activity Fall: 317355.

Korinek, A., 2011. Capital Controls and Currency Wars. Mimeo. University of Maryland.

Korinek, A., 2010. Regulating Capital Flows to Emerging Markets: An Externality View. Mimeo. University of Maryland.

Lechner, M., 2002. Some Practical Issues in the Evaluation of Heterogeneous Labour Market Programmes by Matching Methods. Journal of the Royal Statistical Society, Series A 165 (1): 59-82. 
Leuven, E., Sianesi, B., 2003. PSMATCH2: Stata Module to Perform Full Mahalanobis and Propensity Score Matching, Common Support Graphing, and Covariate Imbalance Testing. Available at: http://ideas.repec.org/c/boc/bocode/s432001.html.

Levchenko, A., Rancière, R., Thoenig, M., 2009. Growth and Risk at the Industry Level: The Real Effects of Financial Liberalization. Journal of Development Economics 89: 210-222.

Lim, C., Columba, F., Costa, A., Kongsamut, P., Otani, A., Saiyid, M., Wezel, T., Wu, X., 2011. Macroprudential Policy: What Instruments and How to Use Them? Lessons from Country Experiences. IMF Working Paper WP/11/238.

Magud, N. E., Reinhart, C. M., Rogoff, K. S., 2011. Capital Controls: Myth and Reality-A Portfolio Balance Approach. Peterson Institute Working Paper 11-7, February.

Ostry, J. D., Ghosh, A. R., Chamon, M., Qureshi, M. S., 2012. Tools for Managing Financial-Stability Risks from Capital Inflows. Journal of International Economics 88(2): 407-421.

Ostry, J. D., Ghosh, A., Habermeier, K., Laeven, L., Chamon, M., Qureshi, M. S., Kokenyne, A., 2011. Managing Capital Inflows: What Tools to Use? IMF Staff Discussion Note SDN/11/06.

Ostry, J. D., Ghosh, A. R., Habermeier, K., Chamon, M., Qureshi, M. S., Reinhardt, D. B. S., 2010. Capital Inflows: The Role of Controls. IMF Staff Position Note SPN/10/04.

Pasricha, G. K., 2012. Recent Trends in Measures to Manage Capital Flows in Emerging Market Economies. The North American Journal of Economics and Finance 23(3): 286-309.

Persson, T., 2001. Currency Unions and Trade: How Large is the Treatment Effect? Economic Policy 16(33): 435-448.

Reinhart, C., Kirkegaard, J., Sbrancia, B., 2011. Financial Repression Redux. MPRA Paper No. 31641. Available at: http://mpra.ub.uni-muenchen.de/31641/.

Rey, H., 2014. Dilemma not Trilemma: The Global Financial Cycle and Monetary Policy Independence. Global Dimensions of Unconventional Monetary Policy, Jackson Hole Symposium on Economic Policy 2013, 284-333.

Rosenbaum, P., Rubin, D., 1985. Constructing a Control Group Using Multivariate Matched Sampling Methods that Incorporate the Propensity Score. The American Statistician 39(1): 33-38.

Rubin, D. B., Thomas, N., 1992. Characterizing the Effect of Matching Using Linear Propensity Score Methods with Normal Distributions. Biometrika 79(4): 797-809.

Schindler, M., 2009. Measuring Financial Integration: A New Data Set. IMF Staff Papers 56(1): 222-238. 


\section{Appendix A \\ Information on Capital-Flow Management Data Set}

The primary source of information for this dataset is the Annual Report on Exchange Arrangements and Exchange Restrictions by the International Monetary Fund for the years 2010-2012. We focus on the end of the section on each country which reports any changes in capital-flow management policies which occurred over the past year. We supplement this source with information from reports by Goldman Sachs, HSBC, Institute of International Finance, JP Morgan Chase, and Morgan Stanley that include information on capital flow policies or country information. We also incorporate information from two papers on capital controls: Magud, Reinhart, and Rogoff (2011) and Reinhart, Kirkegaard, and Sbrancia (2011). Finally, we confirm and add several additional CFM measures using primary news sources.

Examples of the types of CFMs that are included in the database and how they are classified as "capital controls" or "macroprudential measures" are listed in the table below. We only include changes in macroprudential measures if they specifically relate to foreign exchange and/or international exposure.

Types of Capital Flow Management Techniques

\begin{tabular}{|c|c|}
\hline Capital controls & Macroprudential Measures \\
\hline 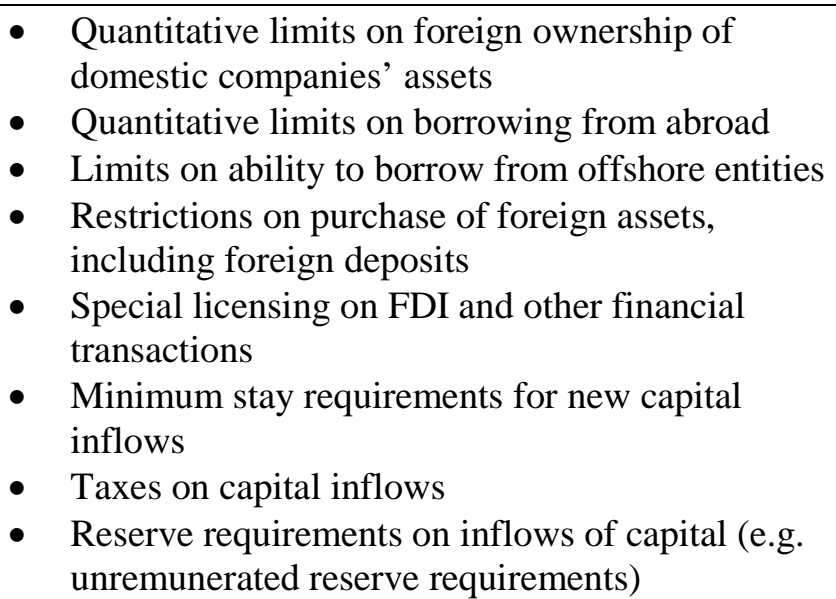 & $\begin{array}{ll}\text { - } & \text { Reporting requirements and limitations on } \\
\text { - } & \text { Restrictions on off-balance-sheet } \\
\text { - } & \text { activities and derivatives contracts } \\
\text { - } & \text { Limits on asset acquisition } \\
\text { - } & \text { Limits on banks' FX positions } \\
\text { - } & \text { Asset classification and provisioning rules } \\
\text { - } & \text { Taxes on FX transactions } \\
\text { - } & \text { Capital requirements on FX assets } \\
\text { - } & \text { Differential reserve requirements on } \\
& \text { liabilities in local and FX currencies }\end{array}$ \\
\hline
\end{tabular}

Measures which are NOT included as CFMs in the database are:

- $\quad$ Changes in macroprudential regulations that are not related to foreign exchange or do not differentially affect foreigners - such as increases in reserve ratios that affect all types of deposits of changes in LTV ratios.

- $\quad$ Limits on capital flows when targeted at specific countries and/or related to sanctions for political reasons (such as restrictions on transactions with Libya or Iran).

- $\quad$ Transactions by the central bank or government in foreign exchange markets aimed at affecting the exchange rate.

- $\quad$ Automatic changes in limits on foreign investment that result from pre-specified indexing to inflation (as occurs in Australia).

- $\quad$ Regulations resulting from specific trade disputes or issues related to one specific industry (including specific restrictions on the oil and gas industry).

- $\quad$ Changes in rules related to foreign purchases of land.

- $\quad$ Minor changes affecting nonresidents living or travelling abroad or residents travelling abroad (such as limits on gifts to family members in different countries, payments for education or medical expenses abroad, or access to foreign currency for travel). 
We use the week of the announcement date of the CFM if it is available, and if not, we use the week of the implementation date as listed in the AREARs. In several cases, multiple CFMs are put into place in the same week. In most of these cases, these measures were aimed at a similar goal and are coded as a single CFM event. For example, in the week of July 1, 2009, Peru enacted capital controls to stem appreciation pressures (a ban on foreign purchases of central bank bills) and increased macroprudential regulations (increased reserve requirements on certain foreign liabilities). In these cases, the week is coded as implementing a new CFM which is both a control on capital inflows and a macroprudential measure, affecting both bonds and banks. In a few cases, countries made multiple changes which may have partially counteracted each other. In these cases, we include the most important control in the database based on the government's intentions according to statements made on the announcement date. ${ }^{38}$

We compile this data on CFMs using a broad sample of countries. We begin with all "Advanced Economies" (as defined by the International Monetary Fund as of October 2012) and all "Emerging Markets" and "Frontier Economies" (as defined by Standard \& Poor’s BMI indices). We then exclude current members of the euro area, the three largest advanced economies (the United States, United Kingdom, and Japan), countries that do not have data on equity or bond flows in the EPFR dataset, and very small countries (with GDP less than $\$ 15$ billion at the end of 2011). ${ }^{39}$ This yields a sample of 60 countries which are listed below.

\section{Countries in the Sample}

\begin{tabular}{cccc}
\hline Argentina & Egypt & Lithuania & Russia \\
Australia & Ghana & Malaysia & Singapore \\
Bahrain & Hong Kong & Mexico & South Africa \\
Botswana & Hungary & Morocco & Sri Lanka \\
Brazil & India & New Zealand & Sweden \\
Bulgaria & Indonesia & Nigeria & Switzerland \\
Canada & Israel & Norway & Taiwan \\
Chile & Jamaica & Oman & Thailand \\
China & Jordan & Pakistan & Trinidad \& Tobago \\
Colombia & Kazakhstan & Panama & Tunisia \\
Cote d'Ivoire & Kenya & Peru & Turkey \\
Croatia & Korea & Philippines & Ukraine \\
Czech Republic & Kuwait & Poland & United Arab Emirates \\
Denmark & Latvia & Qatar & Vietnam \\
Ecuador & Lebanon & Romania & Zambia \\
\hline
\end{tabular}

\footnotetext{
${ }^{38}$ For example, in October 2010 Thailand reinstated a 15\% withholding tax on foreigners' interest and capital gains on new Thai government bonds issued by the government or GSEs. On the same date, the ceiling on foreign currency deposits with local banks was raised. Since the former announcement received substantial attention, but not the later, the first is coded in the data as a new control on capital inflows, but the change in the macroprudential regulation is not included in the dataset.

${ }^{39}$ Countries that are excluded because they do not have data on either equity or bond flows in the EPFR dataset are: Bangladesh, Iceland, Iran, Mauritania, and Moldova. Countries that are excluded because they have GDP less than \$15 billion at the end of 2011 are: Iceland, Mauritania, Mauritius, Moldova, and Namibia.
} 
Appendix B: Data Definitions and Sources

\begin{tabular}{|c|c|}
\hline Variable & Source, Original Frequency, and Other Notes \\
\hline Bank credit & $\begin{array}{l}\text { Private credit by deposit money banks and other } \\
\text { financial institutions as a share of GDP; annual; Source: } \\
\text { World Bank, Global Financial Development Database }\end{array}$ \\
\hline Bank leverage & $\begin{array}{l}\text { Bank credit to bank deposits; annual (only available } \\
\text { through 2010); Source: World Bank, Global Financial } \\
\text { Development Database }\end{array}$ \\
\hline Capital account openness & $\begin{array}{l}\text { Measure constructed from the International Monetary } \\
\text { Fund's AREARs data with a higher value indicating } \\
\text { greater openness; annual; Source: Chinn and Ito (2008), } \\
\text { updated as of 04/24/2013 and available at: } \\
\text { http://web.pdx.edu/ ito/Chinn-Ito_website.htm }\end{array}$ \\
\hline Commodity price index & $\begin{array}{l}\text { Dow Jones AIG commodity index, closing price; } \\
\text { weekly; Source: Global Financial Data }\end{array}$ \\
\hline CPI inflation & $\begin{array}{l}\text { Consumer price index inflation; monthly; Source: } \\
\text { International Monetary Fund, International Financial } \\
\text { Statistics }\end{array}$ \\
\hline CPI inflation forecasts & $\begin{array}{l}\text { 52-week forward consensus expectations of CPI } \\
\text { inflation; monthly; Source: IPA calculations }\end{array}$ \\
\hline Equity market index & $\begin{array}{l}\text { Index based on a broad market measure using end-of- } \\
\text { week prices; weekly; Source: Datastream }\end{array}$ \\
\hline Floating exchange rate regime dummy & $\begin{array}{l}\text { A 0-1 dummy for a floating exchange rate, uses de facto } \\
\text { exchange rate regime (classified as a peg, intermediate, } \\
\text { or floating); annual; Source: Ghosh et al. (2011) }\end{array}$ \\
\hline $\begin{array}{l}\text { Foreign currency liabilities as a share of total } \\
\text { liabilities }\end{array}$ & $\begin{array}{l}\text { Foreign currency denominated liabilities as a share of } \\
\text { total liabilities; quarterly; Source: Haver }\end{array}$ \\
\hline Foreign exchange reserves as a share of GDP & $\begin{array}{l}\text { Monthly; Source: International Fund and IPA } \\
\text { calculations, data for Taiwan from } \\
\text { http://www.cbc.gov.tw/ct.asp?xItem=29908\&ctNode=8 } \\
\text { 59\&mp=2 }\end{array}$ \\
\hline GDP per capita & $\begin{array}{l}\text { In nominal US\$; monthly; Source: International } \\
\text { Monetary Fund's WEO database }\end{array}$ \\
\hline $\begin{array}{l}\text { Interest rate differential between domestic } \\
\text { and U.S. interest rates }\end{array}$ & $\begin{array}{l}\text { Based on three-month Treasury rates except for } \\
\text { volatility calculations is based on overnight interest } \\
\text { rates; weekly; Source: Datastream and IPA calculations }\end{array}$ \\
\hline Legal compliance index & $\begin{array}{l}\text { Index ranging from } 0 \text { (no legal compliance) to } 12 \text { (high } \\
\text { legal compliance); the Legal compliance index = Sum of } \\
\text { Law and Order Index, Bureaucracy Quality Index, and } \\
\text { Legislative Strength Index; List of variables available at: } \\
\text { http://www.prsgroup.com/VariableHelp.aspx and the } \\
\text { Methodology to create this index is at: } \\
\text { http://www.prsgroup.com/ICRG Methodology.aspx; } \\
\text { monthly; Source: ICRG databases }\end{array}$ \\
\hline Nominal effective exchange rate & $\begin{array}{l}\text { Broad index with higher values indicating an } \\
\text { appreciation of the domestic currency; weekly; Source: } \\
\text { Haver and JPMorgan }\end{array}$ \\
\hline Portfolio bond flows & $\begin{array}{l}\text { Net portfolio bond inflows accumulated over past } 13 \\
\text { weeks and usually expressed as a \% of bond assets at the } \\
\text { start of period, in US\$; weekly; Source: EPFR }\end{array}$ \\
\hline
\end{tabular}




\begin{tabular}{|l|l|}
\hline Portfolio equity flows & $\begin{array}{l}\text { Net portfolio equity inflows accumulated over past 13 } \\
\text { weeks and usually expressed as a \% of equity assets at } \\
\text { the start of period, in US\$; weekly; Source: EPFR }\end{array}$ \\
\hline Portfolio flows & $\begin{array}{l}\text { Sum of net portfolio bond and portfolio equity inflows; } \\
\text { accumulated over past 13 weeks and usually expressed } \\
\text { as a \% of bond and equity assets at the start of period, in } \\
\text { US\$; weekly; Source: EPFR }\end{array}$ \\
\hline $\begin{array}{l}\text { Portfolio liabilities as a share of total } \\
\text { liabilities }\end{array}$ & $\begin{array}{l}\text { Portfolio investment liabilities in all sectors as a share of } \\
\text { total liabilities (gross inflows); quarterly; Source: Haver, } \\
\text { based on the International Monetary Fund's BOP }\end{array}$ \\
\hline Private credit & $\begin{array}{l}\text { Expressed in local currency or as a share of GDP; } \\
\text { monthly; Source: International Monetary Fund and IPA } \\
\text { calculations }\end{array}$ \\
\hline Real effective exchange rate & $\begin{array}{l}\text { Broad real exchange rate index average for 44 countries, } \\
\text { with higher values indicating an appreciation of the } \\
\text { domestic currency; monthly; Source: BIS, and if not } \\
\text { available, then from the International Monetary Fund; } \\
\text { series is constructed for Vietnam }\end{array}$ \\
\hline Short-term external debt to GDP & $\begin{array}{l}\text { In millions of US\$; annual; World Bank, Global } \\
\text { Financial Development Database }\end{array}$ \\
\hline Stock market capitalization to GDP & $\begin{array}{l}\text { Annual; Source: World Bank, Global Financial } \\
\text { Development Database }\end{array}$ \\
\hline TED spread & $\begin{array}{l}\text { Difference between the 3-month LIBOR and 3-month } \\
\text { Treasury Bill yield, closing value; weekly; Source: } \\
\text { Global Financial Data }\end{array}$ \\
\hline VIX & $\begin{array}{l}\text { Index of market volatility calculated by the Chicago } \\
\text { Board Options Exchange; measures implied volatility } \\
\text { using prices for a range of options on the S\&P 100 } \\
\text { index.; weekly; Source: Haver }\end{array}$ \\
\hline
\end{tabular}




\section{Appendix C: Propensity-Score Methodology}

To use the propensity-score methodology, define a "treated" observation as $D_{i}=1$, which is any week in which country $i$ changes a CFM. Likewise $D_{i}=0$ are the "untreated" or "control” observations, which are any weeks when country $i$ does not change a CFM. We also create an "exclusion window" for 3 months before and 3 months after a change in the CFM of interest. During this exclusion window a country cannot be used as a control observation — even if it makes no changes to the relevant CFM during those weeks. Also define $Y_{1, i}$ as the outcome variable (such as the change in the exchange rate) for the $i^{\text {th }}$ member of the treated group and $Y_{0, i}$ for the $i^{\text {th }}$ member of the untreated (control) group. Summing over members of each group, we are able to observe $\mathrm{E}\left[Y_{1, i} \mid D_{i}=1\right]$ and $\mathrm{E}\left[Y_{0, i} \mid D_{i}=0\right]$. The variable in which we are interested, however, is the "average treatment effect on the treated" or ATT, which is not observable and is written as:

$$
\mathrm{ATT}=\mathrm{E}\left[Y_{1, i}-Y_{0, i} \mid D_{i}=1\right]
$$

The difference in the two observable statistics is a combination of the key variable of interest (the ATT) and sampling bias:

$$
\begin{aligned}
& \mathrm{E}\left[Y_{1, i} \mid D_{i}=1\right]-\mathrm{E}\left[Y_{0, i} \mid D_{i}=0\right]=\mathrm{E}\left[Y_{1, i}-Y_{0, i} \mid D_{i}=1\right]+\mathrm{E}\left[Y_{0, i} \mid D_{i}=1\right]-\mathrm{E}\left[Y_{0, i} \mid D_{i}=0\right] \\
& =\quad \text { ATT }+ \text { sampling bias . }
\end{aligned}
$$

The sampling bias is the difference in outcomes that is attributable to differences in the treated and control group (such as different country characteristics) rather than any effect of the treatment itself.

To take a simple but concrete example, consider how an increase in macroprudential regulations (the treatment, $D_{i}$ ) affects the real exchange rate $\left(Y_{i}\right)$. Using our dataset described in Section 2, the mean percent change in the real exchange rate over the six months after an increase in macroprudential measures is $1.10 \%$ for the treated sample and $0.78 \%$ for the untreated sample. This could be interpreted as indicating that increasing macroprudential regulations causes an appreciation of the real exchange rate relative to what otherwise would have occurred (ignoring any test for significance or omitted variables). A closer look at the sample of treated and untreated observations, however, indicates that countries that increase their macroprudential regulations over the sample period are also more likely to have a floating 
exchange rate. ${ }^{40}$ More specifically, $80 \%$ of the treated group has a floating exchange rate, as compared to just 39\% of the control group. The different patterns of exchange rate appreciation between the treatment and control groups may therefore result from different exchange rate regimes (selection bias) rather than any effect of changes in macroprudential regulations (the ATT), as specified in equation A2.

Continuing this example, an additional calculation shows that selection bias is, in fact, overwhelming any ATT from increasing macroprudential regulations. We limit the sample to only include countries with floating exchange rates in order to remove any selection bias resulting from this variable and repeat the same calculations as above. The percent change in the real exchange rate over the next six months after an increase in macroprudential regulations is now $0.39 \%$ for the treated sample and $0.84 \%$ for the untreated sample. When focusing only on countries with flexible exchange rates, countries that increased their macroprudential regulations now appear to have less exchange rate appreciation than countries which did not increase regulations_-reversing the earlier pattern. This is obviously not a formal test and ignores many other forms of selection bias and other factors that will be considered in the full analysis. But it does provide a simple example of how selection bias resulting from differences between the treated and control groups can bias estimates of policy effects.

Any sampling bias between the treated and control groups would be straightforward to adjust for if countries differed along only one or two discrete dimensions. If the countries could be easily apportioned to a small number of "cells" reflecting any differences along these dimensions, and there were enough treated and control cases in each cell, it would be simple to calculate the differences between the treated and untreated observations in each cell and take a weighted average of those differences to estimate the effect of different policies. For example, as shown in the simple example above, if the only difference between countries which did and did not adjust macroprudential regulations was whether they had a floating exchange rate, it would be straightforward to divide the sample into treatment and control groups based on their exchange rate regime and then calculate the ATT based on differences in outcomes for treated and untreated countries with the same exchange rate regime.

In practice, however, the differences across countries are multifaceted and numerous, and it is impossible to match two countries which share identical macroeconomic characteristics. Propensity-score matching can address this challenge. This methodology matches countries that undertake the treatments to a subset of countries that do not, based on a set of observable country characteristics and global variables, represented by the vector $X_{i}$ for the $i^{\text {th }}$ country. This matching methodology controls for differences in the

\footnotetext{
${ }^{40}$ Measured using the de facto floating exchange rate regime dummy from Ghosh et al. (2011).
} 
treated and untreated groups that affect outcomes, such that the sampling bias is removed (at least any bias that is captured in the vector $X_{i}$ ). In other words, the key equation summarizing this approach is:

$$
\mathrm{E}\left[\mathrm{Y}_{0, \mathrm{i}} \mid X_{\mathrm{i}}, \mathrm{D}_{\mathrm{i}}=1\right]=\mathrm{E}\left[\mathrm{Y}_{0, \mathrm{i}} \mid X_{i}, \mathrm{D}_{\mathrm{i}}=0\right]
$$

This basically requires that conditional on the vector of observable characteristics, the outcome variable is independent of the treatment status, (i.e., $\mathrm{Y}_{0}, \mathrm{Y}_{1} \perp \mathrm{D}_{\mathrm{i}} \mid X$ ). If this assumption is satisfied, then the ATT can be estimated using two observable terms:

$$
\mathrm{ATT}=\mathrm{E}\left[Y_{1, i} \mid D_{i}=1, X_{i}\right]-\mathrm{E}\left[Y_{0, i} \mid D_{i}=0, X_{i}\right]
$$

This still leaves a multidimensional problem, due to the large set of continuous variables that could be included in $X_{i}$. Rosenbaum and Rubin (1985), however, show that it is sufficient to match treated and control observations based on a "propensity score,” $p\left(X_{i}\right)$, which is a scalar variable that is the probability that country $i$ receives the treatment $\left(D_{i}\right)$. More specifically, the propensity score is:

$$
p\left(X_{i}\right)=\operatorname{Pr}\left[D_{i}=1 \mid X_{i}\right]
$$

In our case, the propensity score is the conditional probability of a country adjusting its CFMs given pretreatment characteristics, $X_{i}$, which include country-specific and global variables. This single propensity score reduces the number of dimensions over which observations must be matched. Rubin and Thomas (1992) show that it is possible to estimate these propensity scores based on the vector of observable characteristics. These propensity scores are traditionally estimated using a logit or probit regression.

After the propensity scores have been estimated, there are several algorithms that can be used to match each treated observation with one or more untreated observations. We focus on five techniques: nearest neighbor without replacement, five-nearest neighbors (with replacement), radius with caliper, kernel, and local-linear. ${ }^{41}$ Each algorithm differs based on the number of observations included in the control set and the weighting of these observations.

\footnotetext{
${ }^{41}$ We apply these matching algorithms with the Stata module PSMATCH2, developed by Leuven and Sianesi (2003). The number of treated observations after matching is lower than reported in Table 1 because data is not available to estimate propensity scores for all observations.
} 
In the simplest technique, nearest-neighbor matching, an observation from the control group is chosen as a match for a treated observation based on which control has the closest propensity score. This method "without replacement” requires that untreated observations are used only once, while this method "with replacement” allows untreated observations to be used more than once as a match. This method can be used with more than one "nearest-neighbor" as a control group—and we also estimate the model using five-nearest neighbors. The radius method uses the same basic approach, except includes all "nearest neighbors” which fall within a maximum radius (referred to as the caliper) based on the estimated propensity scores. $^{42}$ The kernel and local-linear matching algorithms calculate a weighted average of all observations in the control group using nonparametric estimators which use generalized weighting functions to assign a higher weight to control observations closer to the treated observation. ${ }^{43}$ The nearest-neighbor algorithm is basically an extreme form of kernel and local-linear matching, with all weight given to the closest propensity score.

Each of these matching methodologies has advantages and disadvantages. Nearest neighbor is straightforward, easy to implement, and minimizes "bad" matches with control observations that have little in common with the treated observation. It is also straightforward to check which country is “matched” as the nearest neighbor in a control group. Nearest neighbor, however, ignores useful information from other countries in the control group. Radius, kernel, and local-linear matching use more information and therefore tend to have lower variances—-but at the risk of including bad matches. Radius matching is less sophisticated than kernel and local-linear matching as it does not place greater weight on better matches within its "radius”. Fan $(1992,1993)$ shows that local-linear matching has several important advantages over kernel matching, such as a faster rate of convergence near boundary points and greater robustness to different data design densities.

There are several test statistics that can be used to assess the accuracy of the matching and whether the algorithm removes any significant differences between the treated and control groups. The two most critical tests_-of the “Common Support Condition” and "Balancing Assumption”—are discussed in Section 3.3 of the paper. There are also several additional statistics, however, which are useful to evaluate the effectiveness of each algorithm. These are reported in Table A1 for each of the three CFMs. Each section of the table lists the mean propensity scores for the treatment group, unmatched control group, and matched control group using each algorithm. In most cases, the mean propensity score for the control

\footnotetext{
${ }^{42}$ We set the caliper at 0.005 .

43 The main difference between the two methods is the weighting functions. See Heckman, Ichimura, and Todd (1997, 1998) for a detailed description of the local-linear matching method.
} 
group is closer to that of the treatment group after matching, indicating that the matched control group is more "similar" to the treatment group than the unmatched control group. According to this comparison, however, there is no matching algorithm that consistently performs best; local-linear matching yields a mean closest to the treatment group for inflow controls, nearest-neighbor is closest for macroprudential measures, and kernel is closest for outflow controls.

Table A1 also reports the mean absolute bias (and standard deviation) of the treatment group relative to the unmatched control group and control groups using each of the matching algorithms. In each case, the matching reduces the mean absolute bias by a substantial amount, with different matching algorithms again performing better or worse based on the treatment. These statistics also capture the bias/efficiency trade-off inherent in selecting a matching technique. Methodologies such as nearest neighbor that only use one observation as the control group tend to have a lower mean absolute bias (as it only uses the most similar observation), but at the cost of ignoring other useful information and therefore having more imprecise estimates (and higher standard deviations). Methods that incorporate more observations in the control group (such as local-linear and kernel matching) should be more efficient as they incorporate more information, but at the cost of potentially have greater mean bias due to including poorer matches. There is no standard procedure to select a preferred matching algorithm based on this bias/efficiency tradeoff. 
Table 1

Capital-Flow Management Measures

\begin{tabular}{|c|c|c|c|c|c|c|c|c|c|}
\hline & \multicolumn{2}{|c|}{$\begin{array}{l}\text { Controls on } \\
\text { Inflows }\end{array}$} & \multicolumn{2}{|c|}{$\begin{array}{l}\text { Controls on } \\
\text { Outflows }\end{array}$} & \multicolumn{2}{|c|}{$\begin{array}{c}\text { Macroprudential } \\
\text { Measures }\end{array}$} & \multicolumn{2}{|c|}{$\begin{array}{l}\text { Related to Pressures } \\
\text { From Capital: }\end{array}$} & \multirow[b]{2}{*}{ Tota } \\
\hline & - & + & - & + & - & + & Outflows & Inflows & \\
\hline Argentina & 3 & 2 & 3 & 1 & 2 & 1 & 6 & 6 & 12 \\
\hline Brazil & 1 & 7 & 0 & 0 & 0 & 2 & 1 & 9 & 10 \\
\hline Bulgaria & 1 & 0 & 1 & 0 & 0 & 0 & 1 & 1 & 2 \\
\hline Chile & 0 & 0 & 1 & 0 & 0 & 0 & 0 & 1 & 1 \\
\hline China & 4 & 0 & 2 & 0 & 2 & 0 & 6 & 2 & 8 \\
\hline Colombia & 1 & 0 & 1 & 1 & 1 & 2 & 3 & 3 & 6 \\
\hline Côte d'Ivoire & 0 & 0 & 0 & 1 & 0 & 0 & 1 & 0 & 1 \\
\hline Croatia & 1 & 0 & 3 & 1 & 3 & 2 & 5 & 5 & 10 \\
\hline Czech Republic & 0 & 0 & 1 & 0 & 0 & 1 & 0 & 2 & 2 \\
\hline Ecuador & 0 & 0 & 0 & 1 & 0 & 0 & 1 & 0 & 1 \\
\hline Ghana & 0 & 0 & 0 & 0 & 0 & 1 & 0 & 1 & 1 \\
\hline Hungary & 0 & 0 & 0 & 0 & 1 & 2 & 1 & 2 & 3 \\
\hline India & 4 & 0 & 0 & 0 & 1 & 2 & 5 & 2 & 7 \\
\hline Indonesia & 0 & 2 & 0 & 0 & 0 & 4 & 0 & 6 & 6 \\
\hline Israel & 0 & 0 & 0 & 0 & 0 & 2 & 0 & 2 & 2 \\
\hline Jamaica & 0 & 0 & 0 & 0 & 1 & 2 & 1 & 2 & 3 \\
\hline Kazakhstan & 1 & 0 & 2 & 1 & 1 & 1 & 3 & 3 & 6 \\
\hline Kenya & 0 & 0 & 0 & 0 & 0 & 1 & 0 & 1 & 1 \\
\hline Korea (South) & 0 & 2 & 1 & 0 & 0 & 6 & 0 & 9 & 9 \\
\hline Latvia & 0 & 0 & 0 & 0 & 0 & 2 & 0 & 2 & 2 \\
\hline Lebanon & 0 & 0 & 1 & 0 & 0 & 2 & 0 & 3 & 3 \\
\hline Malaysia & 2 & 0 & 3 & 0 & 3 & 0 & 5 & 3 & 8 \\
\hline Mexico & 1 & 0 & 0 & 0 & 0 & 0 & 1 & 0 & 1 \\
\hline Morocco & 0 & 0 & 2 & 0 & 3 & 0 & 3 & 2 & 5 \\
\hline Nigeria & 1 & 0 & 0 & 0 & 0 & 0 & 1 & 0 & 1 \\
\hline Oman & 0 & 0 & 1 & 0 & 0 & 0 & 0 & 1 & 1 \\
\hline Pakistan & 0 & 1 & 0 & 0 & 1 & 1 & 1 & 2 & 3 \\
\hline Peru & 0 & 1 & 0 & 0 & 2 & 14 & 2 & 15 & 17 \\
\hline Philippines & 1 & 0 & 3 & 0 & 3 & 0 & 4 & 3 & 7 \\
\hline Romania & 0 & 0 & 0 & 0 & 3 & 1 & 3 & 1 & 4 \\
\hline Russia & 0 & 0 & 0 & 0 & 0 & 9 & 0 & 9 & 9 \\
\hline South Africa & 4 & 0 & 8 & 0 & 1 & 0 & 5 & 8 & 13 \\
\hline Sri Lanka & 2 & 0 & 2 & 0 & 1 & 0 & 3 & 2 & 5 \\
\hline Taiwan & 0 & 0 & 0 & 0 & 0 & 2 & 0 & 2 & 2 \\
\hline Thailand & 0 & 1 & 2 & 0 & 1 & 0 & 1 & 3 & 4 \\
\hline Tunisia & 0 & 0 & 1 & 0 & 1 & 0 & 1 & 1 & 2 \\
\hline Turkey & 0 & 0 & 2 & 0 & 5 & 4 & 5 & 6 & 11 \\
\hline Ukraine & 2 & 1 & 1 & 0 & 11 & 5 & 13 & 7 & 20 \\
\hline Vietnam & 0 & 4 & 0 & 1 & 2 & 3 & 3 & 7 & 10 \\
\hline Total & 29 & 21 & 42 & 7 & 49 & 72 & 85 & 135 & 220 \\
\hline
\end{tabular}

Notes: The "-" denotes the removal or easing of a control or macroprudential measure and the "+" denotes the addition or tightening of measure. Countries included in the sample which do not have a CFM event are: Australia, Bahrain, Botswana, Canada, Denmark, Egypt, Hong Kong, Jordan, Kuwait, Lithuania, New Zealand, Norway, Panama, Poland, Qatar, Singapore, Sweden, Switzerland, Trinidad and Tobago, United Arab Emirates, and Zambia. 
Table 2

Predicting Real Exchange Rate Movements: OLS and Selection Bias

\begin{tabular}{|c|c|c|c|c|c|c|c|}
\hline & \multicolumn{3}{|c|}{ Full Sample } & \multicolumn{2}{|c|}{$\begin{array}{c}\text { Floating Exchange } \\
\text { Rate Regimes ONLY }\end{array}$} & \multicolumn{2}{|c|}{$\begin{array}{c}\text { Excluding Floating } \\
\text { Exchange Rate Regimes }\end{array}$} \\
\hline & (1) & (2) & (3) & (4) & (5) & (6) & (7) \\
\hline $\begin{array}{l}\text { Increased macroprudential } \\
\text { regulations dummy }\end{array}$ & $\begin{array}{l}0.012^{* *} \\
(0.005)\end{array}$ & $\begin{array}{l}0.013^{* *} \\
(0.005)\end{array}$ & $\begin{array}{l}0.010^{*} \\
(0.005)\end{array}$ & $\begin{array}{c}0.004 \\
(0.005)\end{array}$ & $\begin{array}{c}0.004 \\
(0.005)\end{array}$ & $\begin{array}{c}0.041^{* * *} \\
(0.013)\end{array}$ & $\begin{array}{c}0.051^{* * *} \\
(0.016)\end{array}$ \\
\hline $\begin{array}{l}\text { Floating exchange rate } \\
\text { dummy }^{1}\end{array}$ & & $\begin{array}{l}-0.000 \\
(0.001)\end{array}$ & $\begin{array}{l}0.002 * \\
(0.001)\end{array}$ & & & & \\
\hline $\begin{array}{l}\text { Portfolio flows over last } 6 \\
\text { months (\% change) }\end{array}$ & & & $\begin{array}{l}0.000^{*} \\
(0.000)\end{array}$ & & $\begin{array}{c}0.000 \\
(0.000)\end{array}$ & & $\begin{array}{c}0.000 \\
(0.000)\end{array}$ \\
\hline $\begin{array}{l}\text { Consensus CPI, } \\
\text { 52-week expectations }\end{array}$ & & & $\begin{array}{c}0.001 * * * \\
(0.000)\end{array}$ & & $\begin{array}{l}-0.000 \\
(0.000)\end{array}$ & & $\begin{array}{c}0.001^{* * *} \\
(0.000)\end{array}$ \\
\hline $\begin{array}{l}\text { Private credit to GDP } \\
\text { (\% change) }\end{array}$ & & & $\begin{array}{c}-0.011 * * * \\
(0.004)\end{array}$ & & $\begin{array}{c}-0.032 * * * \\
(0.008)\end{array}$ & & $\begin{array}{c}0.000 \\
(0.005)\end{array}$ \\
\hline VIX & & & $\begin{array}{c}-0.001 * * * \\
(0.000)\end{array}$ & & $\begin{array}{c}-0.002 * * * \\
(0.000)\end{array}$ & & $\begin{array}{c}-0.000^{* * *} \\
(0.000)\end{array}$ \\
\hline TED Spread & & & $\begin{array}{c}-0.003^{* * *} \\
(0.001)\end{array}$ & & $\begin{array}{c}-0.004 * * * \\
(0.001)\end{array}$ & & $\begin{array}{c}-0.005^{* * *} \\
(0.002)\end{array}$ \\
\hline $\begin{array}{l}\text { Commodity prices } \\
\text { (\% change) }\end{array}$ & & & $\begin{array}{c}-0.020^{* * * *} \\
(0.003)\end{array}$ & & $\begin{array}{c}-0.039 * * * \\
(0.004)\end{array}$ & & $\begin{array}{c}0.006 \\
(0.004)\end{array}$ \\
\hline $\begin{array}{l}\text { Interest rate vs. US rate } \\
\text { (change in spread) }\end{array}$ & & & $\begin{array}{c}-0.000^{* *} \\
(0.000)\end{array}$ & & $\begin{array}{c}-0.001^{* * *} \\
(0.000)\end{array}$ & & $\begin{array}{l}-0.000 \\
(0.000)\end{array}$ \\
\hline $\begin{array}{l}\text { FX Reserves/GDP } \\
\text { (\% change) }\end{array}$ & & & $\begin{array}{c}0.006 * * * \\
(0.001)\end{array}$ & & $\begin{array}{c}0.008^{* * *} \\
(0.002)\end{array}$ & & $\begin{array}{c}0.006 * * * \\
(0.002)\end{array}$ \\
\hline Capital account openness & & & $\begin{array}{c}0.002 * * * \\
(0.000)\end{array}$ & & $\begin{array}{c}0.001 \\
(0.001)\end{array}$ & & $\begin{array}{c}0.003 * * * \\
(0.001)\end{array}$ \\
\hline $\begin{array}{l}\text { Stock market cap. } \\
\text { (\% of GDP) }\end{array}$ & & & $\begin{array}{l}-0.000 \\
(0.000)\end{array}$ & & $\begin{array}{l}-0.000 \\
(0.000)\end{array}$ & & $\begin{array}{l}-0.000 \\
(0.000)\end{array}$ \\
\hline Log GDP per capita & & & $\begin{array}{c}-0.002 * * * \\
(0.001)\end{array}$ & & $\begin{array}{c}-0.005^{* * *} \\
(0.001)\end{array}$ & & $\begin{array}{c}-0.005^{* * *} \\
(0.001)\end{array}$ \\
\hline Legal compliance & & & $\begin{array}{c}-0.204^{* * *} \\
(0.046)\end{array}$ & & $\begin{array}{c}-0.729 * * * \\
(0.069)\end{array}$ & & $\begin{array}{c}0.000 \\
(0.059)\end{array}$ \\
\hline $\begin{array}{l}\text { Legal compliance } \\
\text { Squared }\end{array}$ & & & $\begin{array}{c}0.049 * * * \\
(0.011)\end{array}$ & & $\begin{array}{c}0.169 * * * \\
(0.016)\end{array}$ & & $\begin{array}{c}0.002 \\
(0.014)\end{array}$ \\
\hline Constant & $\begin{array}{c}0.004^{* * * *} \\
(0.000)\end{array}$ & $\begin{array}{c}0.004^{* * * *} \\
(0.000)\end{array}$ & $\begin{array}{c}0.254^{* * * *} \\
(0.051)\end{array}$ & $\begin{array}{c}0.004^{* * * *} \\
(0.000)\end{array}$ & $\begin{array}{c}0.878 * * * \\
(0.078)\end{array}$ & $\begin{array}{c}0.004^{* * * *} \\
(0.000)\end{array}$ & $\begin{array}{c}0.036 \\
(0.066)\end{array}$ \\
\hline $\begin{array}{l}\text { Observations } \\
R^{2}\end{array}$ & $\begin{array}{c}21,281 \\
0.000\end{array}$ & $\begin{array}{c}19,019 \\
0.000\end{array}$ & $\begin{array}{c}10,686 \\
0.098\end{array}$ & $\begin{array}{l}8,964 \\
0.000\end{array}$ & $\begin{array}{l}6,129 \\
0.174\end{array}$ & $\begin{array}{c}10,055 \\
0.002\end{array}$ & $\begin{array}{l}4,557 \\
0.067\end{array}$ \\
\hline
\end{tabular}

Notes: OLS regressions predicting the percent change in the real exchange rate over the next quarter (13 weeks). Control variables are all lagged by one period and defined in Appendix B and Table 3. Robust standard errors. *** denotes significance at the $1 \%$ level, ** at the $5 \%$ level and * at the $10 \%$ level.

(1) Floating exchange rate dummy is the de facto measure from Ghosh et al. (2011).

(2) Increased macroprudential regulations dummy is a dummy equal to 1 if the country has increased macroprudential regulations in the current week, as defined in the database defined in Appendix A. 
Table 3

First-Stage Logit Regression Results Used to Calculate Propensity Scores

\begin{tabular}{|c|c|c|c|}
\hline & $\begin{array}{c}\text { Controls on } \\
\text { Capital Inflows } \\
\text { (Increases) }\end{array}$ & $\begin{array}{c}\text { Controls on } \\
\text { Capital Outflows } \\
\text { (Decreases) }\end{array}$ & $\begin{array}{c}\text { Macroprudential } \\
\text { Measures } \\
\text { (Increases) } \\
\end{array}$ \\
\hline \multirow{2}{*}{$\begin{array}{l}\text { Real exchange rate } \\
\text { (\% change) }\end{array}$} & $11.222^{* * *}$ & $6.006 * *$ & 1.317 \\
\hline & (3.045) & (2.679) & (1.937) \\
\hline \multirow{2}{*}{$\begin{array}{l}\text { Portfolio flows over last } 6 \text { months } \\
\text { (\% change) }\end{array}$} & 0.001 & 0.004 & 0.000 \\
\hline & $(0.001)$ & $(0.004)$ & $(0.001)$ \\
\hline \multirow{2}{*}{$\begin{array}{l}\text { Consensus CPI, } \\
\text { 52-week expectations }\end{array}$} & $0.207^{*}$ & -0.148 & $0.337 * * *$ \\
\hline & $(0.123)$ & $(0.098)$ & $(0.067)$ \\
\hline \multirow{2}{*}{$\begin{array}{l}\text { Private credit to GDP } \\
\text { (\% change) }\end{array}$} & 0.652 & 1.157 & $4.501^{* *}$ \\
\hline & $(2.904)$ & $(2.776)$ & $(1.778)$ \\
\hline \multirow[t]{2}{*}{ VIX } & 0.052 & -0.032 & -0.045 \\
\hline & $(0.046)$ & $(0.047)$ & $(0.028)$ \\
\hline \multirow[t]{2}{*}{ TED Spread } & -2.381 & 1.077 & -0.646 \\
\hline & $(1.693)$ & $(1.744)$ & $(0.972)$ \\
\hline \multirow[t]{2}{*}{ Commodity prices (\% change) } & -0.334 & $-2.536^{*}$ & 0.217 \\
\hline & $(1.778)$ & $(1.343)$ & $(0.832)$ \\
\hline \multirow{2}{*}{$\begin{array}{l}\text { Interest rate vs. US } \\
\text { (change in overnight rate) }\end{array}$} & -0.037 & -0.031 & 0.042 \\
\hline & $(0.143)$ & $(0.069)$ & $(0.055)$ \\
\hline \multirow{2}{*}{$\begin{array}{l}\text { FX Reserves/GDP } \\
\text { (\% change) }\end{array}$} & -0.663 & -0.846 & -0.817 \\
\hline & $(0.798)$ & $(0.773)$ & $(0.731)$ \\
\hline \multirow[t]{2}{*}{ Floating ER dummy } & -0.349 & 0.488 & $1.615^{* * *}$ \\
\hline & $(0.535)$ & $(0.572)$ & $(0.367)$ \\
\hline \multirow[t]{2}{*}{ Capital account openness } & -0.097 & $-1.008 * * *$ & $0.579 * * *$ \\
\hline & $(0.369)$ & $(0.242)$ & $(0.149)$ \\
\hline \multirow{2}{*}{$\begin{array}{l}\text { Stock market capitalization } \\
\text { (\% of GDP) }\end{array}$} & $-0.012^{*}$ & $0.006 * *$ & -0.000 \\
\hline & $(0.006)$ & $(0.003)$ & $(0.001)$ \\
\hline \multirow[t]{2}{*}{ Log GDP per capita } & 0.224 & $0.802^{* *}$ & 0.052 \\
\hline & $(0.398)$ & $(0.354)$ & $(0.225)$ \\
\hline \multirow[t]{2}{*}{ Legal compliance } & -17.397 & $105.058^{* *}$ & $79.502 * * *$ \\
\hline & (21.175) & $(42.824)$ & $(24.894)$ \\
\hline \multirow[t]{2}{*}{ Legal compliance squared } & 3.100 & $-25.638 * *$ & $-18.826 * * *$ \\
\hline & $(5.031)$ & $(10.254)$ & $(5.837)$ \\
\hline Observations & 4,953 & 4,708 & 4,394 \\
\hline Pseudo $R^{2}$ & 0.192 & 0.222 & 0.155 \\
\hline
\end{tabular}

Notes: Results of logit regressions predicting the probability of a change in the CFM listed at the top in each week. CFM events are summarized in Table 1 and an "exclusion window" is created for the 3 months before and after each event. Explanatory variables are defined in Appendix B. Robust standard errors. Changes are calculated over 52 weeks in order to adjust for any seasonal effects. Constant is included in regression and not reported above.* indicates significant at the $10 \%$ level, ** at the $5 \%$ level and $* * *$ at the $1 \%$ level. 
Table 4

Increased Controls on Capital Inflows:

Means for Treated and Control Groups using Different Matching Algorithms

\begin{tabular}{|c|c|c|c|c|c|c|c|c|c|c|c|c|c|}
\hline & \multirow{2}{*}{$\begin{array}{c}\text { Mean: } \\
\text { Treated } \\
\text { Group } \\
\left(\mu_{T}\right)\end{array}$} & \multirow{2}{*}{$\begin{array}{c}\text { Mean: } \\
\text { Unmatched } \\
\text { Control } \\
\left(\mu_{C}\right)\end{array}$} & \multirow{2}{*}{$\begin{array}{c}t- \\
\text { Statistics } \\
\left(H 0: \mu_{T}=\right. \\
\left.\mu_{C}\right)\end{array}$} & \multicolumn{2}{|c|}{$\begin{array}{l}\text { Nearest Neighbor } \\
\text { (no replacement) }\end{array}$} & \multicolumn{2}{|c|}{$\begin{array}{l}\text { 5-Nearest } \\
\text { Neighbors }\end{array}$} & \multicolumn{2}{|c|}{$\begin{array}{c}\text { Radius with } \\
\text { Caliper }\end{array}$} & \multicolumn{2}{|c|}{ Kernel } & \multicolumn{2}{|c|}{ Local-linear } \\
\hline & & & & $\begin{array}{c}\text { Mean: } \\
\text { Matched } \\
\text { Control } \\
\end{array}$ & $t$-stat & $\begin{array}{c}\text { Mean: } \\
\text { Matched } \\
\text { Control } \\
\end{array}$ & $t$-stat & $\begin{array}{c}\text { Mean: } \\
\text { Matched } \\
\text { Control } \\
\end{array}$ & $t$-stat & $\begin{array}{c}\text { Mean } \\
\text { Matched } \\
\text { Control } \\
\end{array}$ & t-stat & $\begin{array}{c}\text { Mean } \\
\text { Matched } \\
\text { Control } \\
\end{array}$ & $t$-stat \\
\hline Real ER & 0.090 & 0.008 & $4.21^{* * *}$ & 0.093 & -0.12 & 0.100 & -0.32 & 0.068 & -0.15 & 0.039 & 1.36 & 0.099 & -0.33 \\
\hline Portfolio flows & 0.401 & -2.541 & 0.21 & 3.346 & -0.99 & -9.611 & 0.46 & -1.073 & 0.15 & -2.163 & 0.19 & 1.955 & -0.58 \\
\hline Consensus CPI & 7.156 & 4.158 & $4.78 * * *$ & 6.675 & 0.43 & 6.620 & 0.49 & 6.492 & 0.14 & 4.433 & $2.30 * *$ & 6.115 & 1.03 \\
\hline Credit growth & 0.044 & 0.026 & 0.99 & 0.021 & 0.75 & 0.027 & 0.57 & 0.037 & 0.34 & 0.030 & 0.52 & 0.012 & 1.12 \\
\hline VIX & 25.752 & 26.482 & -0.39 & 28.132 & -0.93 & 24.917 & 0.35 & 25.592 & -0.43 & 26.357 & -0.51 & 27.791 & -0.82 \\
\hline TED & 0.268 & 0.351 & -1.39 & 0.275 & -0.17 & 0.244 & 0.52 & 0.292 & -0.32 & 0.331 & -0.88 & 0.271 & -0.08 \\
\hline Commodities & 0.068 & -0.007 & 1.30 & 0.038 & 0.48 & 0.090 & -0.35 & 0.057 & 0.02 & 0.016 & 0.64 & 0.058 & 0.18 \\
\hline Interest rate - US & -0.523 & -0.149 & -0.56 & -0.596 & 0.03 & -1.093 & 0.25 & -0.423 & -0.16 & -0.396 & -0.16 & -1.006 & 0.22 \\
\hline FX Reserves/GDP & 0.080 & 0.084 & -0.06 & 0.108 & -0.37 & 0.089 & -0.13 & 0.085 & -0.01 & 0.095 & -0.20 & 0.134 & -0.73 \\
\hline Floating ER & 0.667 & 0.744 & -0.81 & 0.714 & -0.33 & 0.667 & 0.00 & 0.681 & 0.26 & 0.760 & -0.42 & 0.714 & -0.33 \\
\hline CA openness & 0.073 & 1.016 & $-2.97 * * *$ & 0.159 & -0.27 & 0.126 & -0.16 & 0.259 & -0.47 & 0.874 & $-2.07 * *$ & 0.234 & -0.51 \\
\hline Stock market cap. & 43.231 & 84.666 & $-1.98^{* *}$ & 47.565 & -0.36 & 47.698 & -0.41 & 52.349 & -0.44 & 78.437 & -1.61 & 48.162 & -0.40 \\
\hline GDP per capita & 8.443 & 9.295 & $-3.26 * * *$ & 8.498 & -0.19 & 8.429 & 0.05 & 8.575 & -0.04 & 9.200 & $-2.04 * *$ & 8.535 & -0.31 \\
\hline Legal compliance & 2.046 & 2.229 & $-3.82 * * *$ & 2.033 & 0.26 & 2.045 & 0.03 & 2.094 & -0.96 & 2.180 & $-2.16^{* *}$ & 2.029 & 0.32 \\
\hline Legal comp. $^{2}$ & 4.216 & 5.018 & $-3.76^{* * *}$ & 4.157 & 0.27 & 4.212 & 0.02 & 4.425 & -0.97 & 4.807 & $-2.20 * *$ & 4.144 & 0.33 \\
\hline $\begin{array}{l}\text { Mean Propensity } \\
\text { Score }\end{array}$ & 420.6 & 498.7 & & 499.3 & & 446.8 & & 491.4 & & 466.8 & & 445.3 & \\
\hline Observations & 21 & 4932 & & 21 & & 21 & & 18 & & 20 & & 21 & \\
\hline
\end{tabular}

Notes: Reports difference in means between treated and control groups, with control group created based on regression results reported in Table 3 and matching performed using algorithms listed at top. See Table 3 and Appendix B for detailed variable definitions. * indicates significant at the $10 \%$ level, ** at the $5 \%$ level, and *** at the $1 \%$ level. 


\section{Appendix Table A1}

Summary of Results for Different Matching Algorithms

\begin{tabular}{|c|c|c|c|c|c|c|c|}
\hline & \multirow[b]{2}{*}{$\begin{array}{c}\text { Treatment } \\
\text { Group }\end{array}$} & \multirow[b]{2}{*}{$\begin{array}{l}\text { Unmatched } \\
\text { Control } \\
\text { Group }\end{array}$} & \multicolumn{5}{|c|}{ Matched Control Group Based on Matching Algorithm: } \\
\hline & & & $\begin{array}{c}\text { Nearest } \\
\text { Neighbor (no } \\
\text { replacement) }\end{array}$ & $\begin{array}{l}5 \text { Nearest } \\
\text { Neighbors }\end{array}$ & $\begin{array}{l}\text { Radius with } \\
\text { Caliper }\end{array}$ & Kernel & $\begin{array}{l}\text { Local- } \\
\text { linear }\end{array}$ \\
\hline \multicolumn{8}{|c|}{ Increased controls on capital inflows } \\
\hline Mean propensity score & 420.6 & 498.7 & 499.3 & 446.8 & 491.4 & 466.8 & 445.3 \\
\hline $\begin{array}{l}\text { Mean absolute bias } \\
\text { (standard deviation) }\end{array}$ & & $\begin{array}{c}47.32 \\
(36.68)\end{array}$ & $\begin{array}{c}9.93 \\
(7.96)\end{array}$ & $\begin{array}{c}8.21 \\
(6.95)\end{array}$ & $\begin{array}{l}10.17 \\
(9.53)\end{array}$ & $\begin{array}{c}36.89 \\
(27.11)\end{array}$ & $\begin{array}{c}12.94 \\
(10.35)\end{array}$ \\
\hline Observations on support & 21 & 4932 & 21 & 21 & 18 & 20 & 21 \\
\hline \multicolumn{8}{|c|}{ Increased macroprudential measures } \\
\hline Mean propensity score & 548.1 & 476.7 & 548.7 & 564.5 & 566.6 & 521.3 & 588.3 \\
\hline $\begin{array}{l}\text { Mean absolute bias } \\
\text { (standard deviation) }\end{array}$ & & $\begin{array}{c}33.15 \\
(21.13)\end{array}$ & $\begin{array}{c}8.15 \\
(6.01)\end{array}$ & $\begin{array}{c}5.42 \\
(3.73)\end{array}$ & $\begin{array}{c}3.23 \\
(1.98)\end{array}$ & $\begin{array}{c}18.27 \\
(11.96)\end{array}$ & $\begin{array}{c}8.01 \\
(5.37)\end{array}$ \\
\hline Observations on support & 59 & 4335 & 59 & 59 & 58 & 59 & 59 \\
\hline \multicolumn{8}{|c|}{ Decreased controls on capital outflows } \\
\hline Mean propensity score & 439.0 & 496.8 & 559.2 & 506.9 & 487.3 & 464.3 & 495.4 \\
\hline $\begin{array}{l}\text { Mean absolute bias } \\
\text { (standard deviation) }\end{array}$ & & $\begin{array}{c}38.50 \\
(32.83)\end{array}$ & $\begin{array}{l}10.29 \\
(6.32)\end{array}$ & $\begin{array}{c}6.17 \\
(3.20)\end{array}$ & $\begin{array}{c}6.19 \\
(4.42)\end{array}$ & $\begin{array}{l}9.19 \\
(6.48)\end{array}$ & $\begin{array}{l}21.55 \\
(20.38)\end{array}$ \\
\hline Observations on support & 29 & 4679 & 29 & 29 & 27 & 29 & 29 \\
\hline
\end{tabular}

Notes: Statistics and tests from use of matching algorithms discussed in Section 3.3 and Appendix C. 
Figure 1

Incidence of Different Types of CFMs: 2009 - 2011
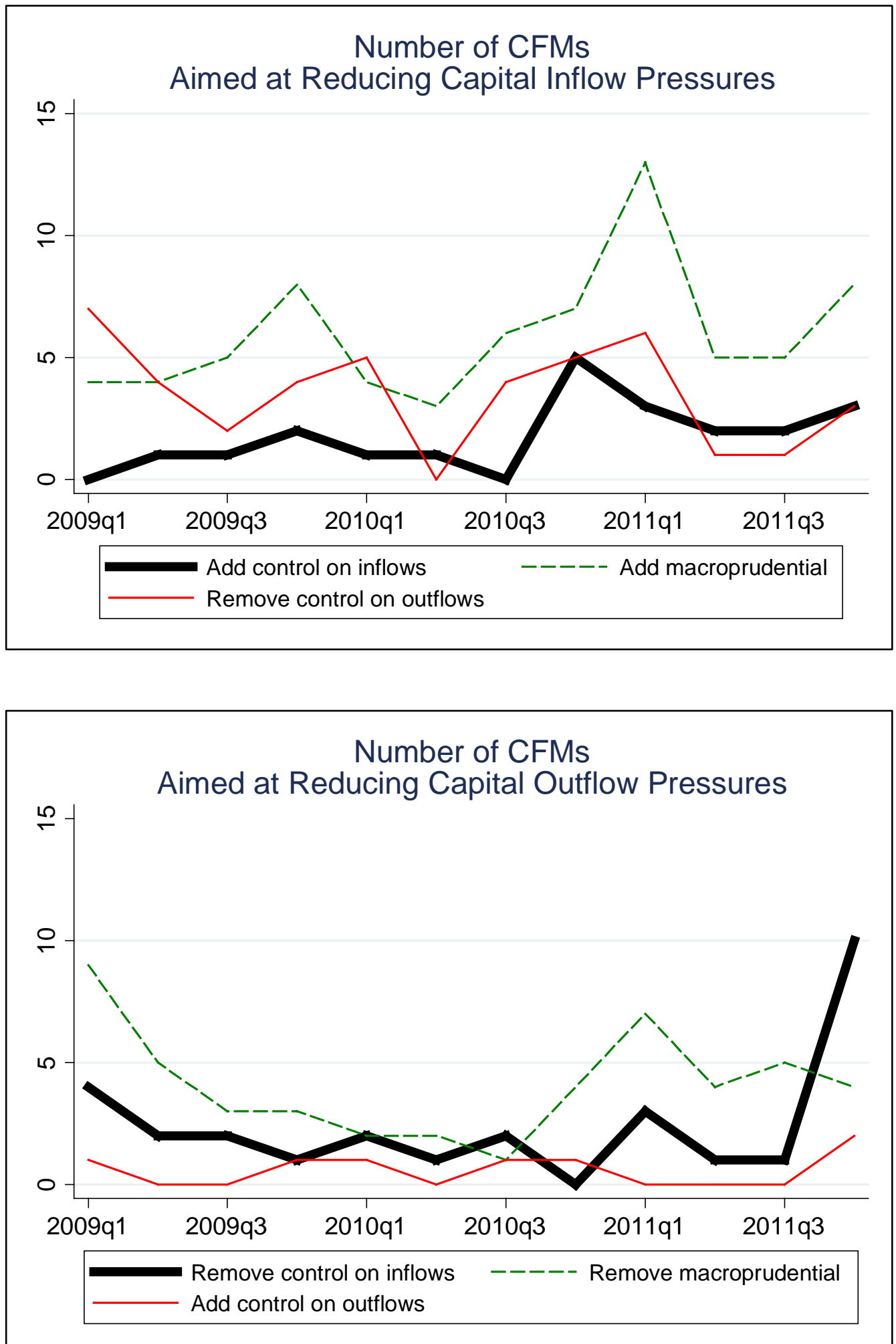


\section{Figure 2a}

\section{Average Treatment Effects of CFMs Using Local-Linear Matching: Exchange Rates and Portfolio Flows}

\% Change in Nominal Exchange Rate

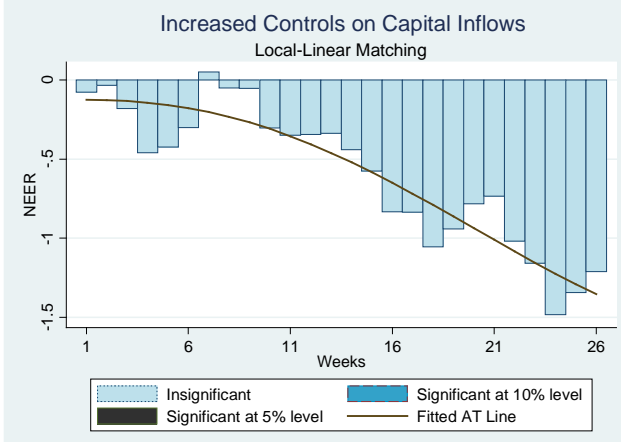

Decreased Controls on Capital Outflows

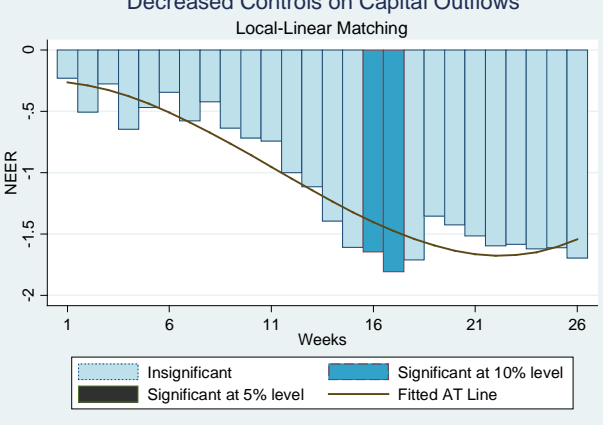

Increased Prudential Measures

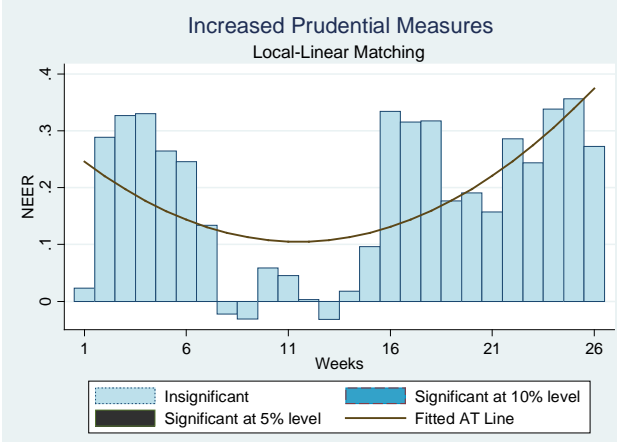

\% Change in Real Exchange Rate

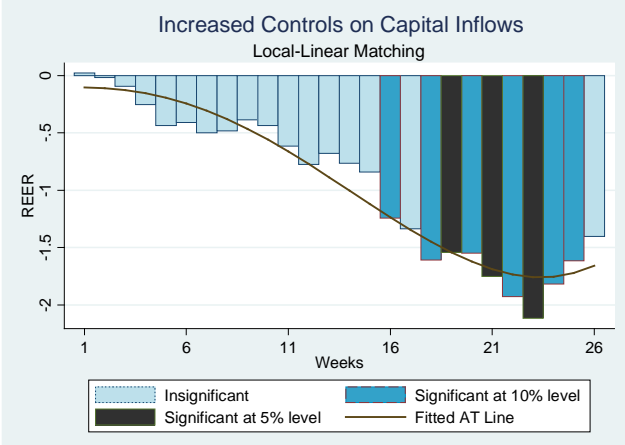

Decreased Controls on Capital Outflows

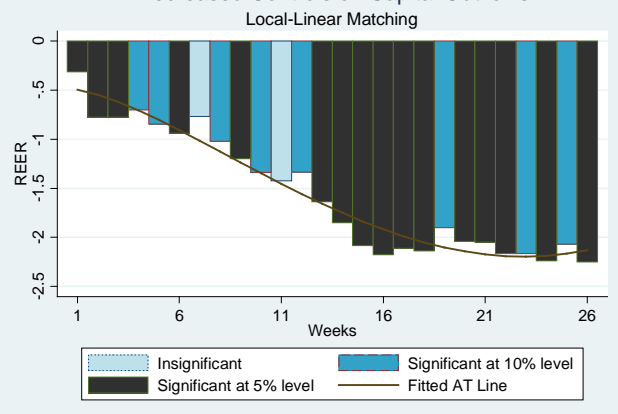

Increased Prudential Measures

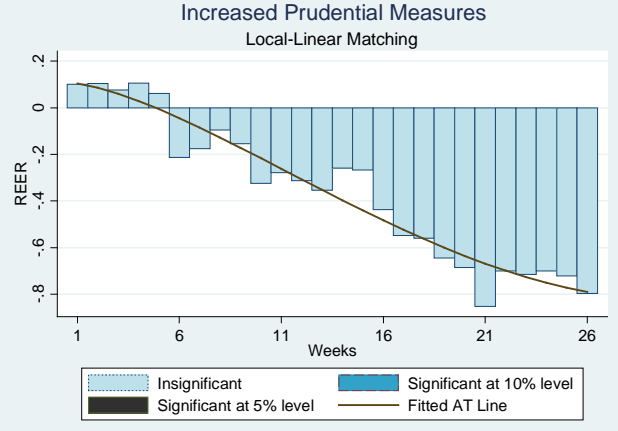

Change in Net Portfolio Inflows

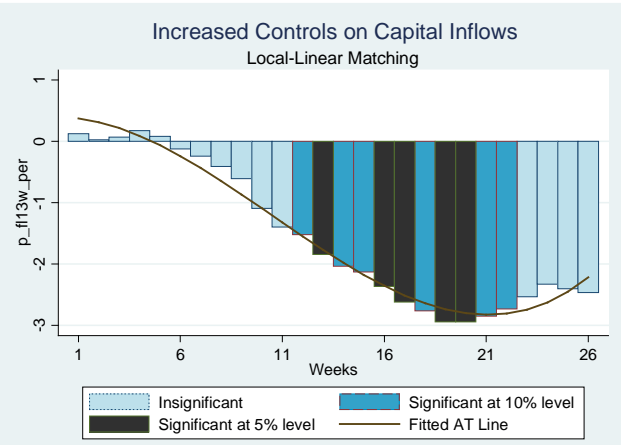

Decreased Controls on Capital Outflows

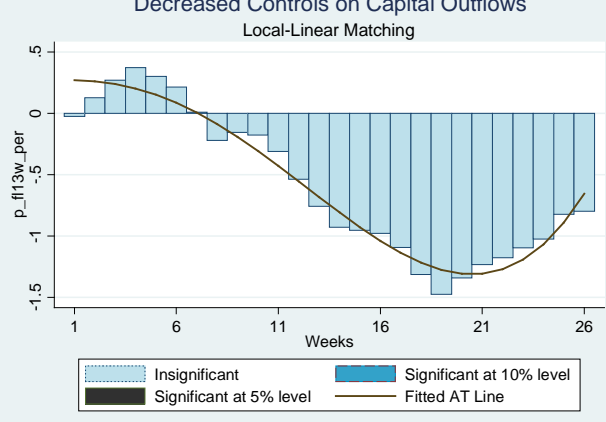

Increased Prudential Measures

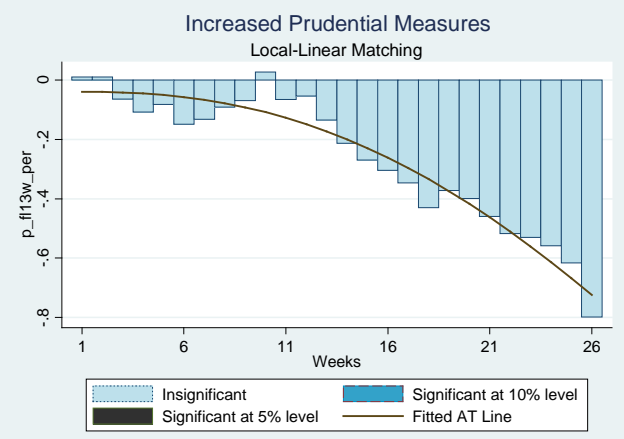

Notes: (1) Based on a broad exchange rate index. (2) Net portfolio inflows are cumulative flows over the last 13 weeks and measured as a percent of total portfolio assets lagged one period before the CFM event. 
Figure 2b

Average Treatment Effects of CFMs Using Five-Nearest Neighbors: Exchange Rates and Portfolio Flows

\% Change in Nominal Exchange Rate ${ }^{1}$

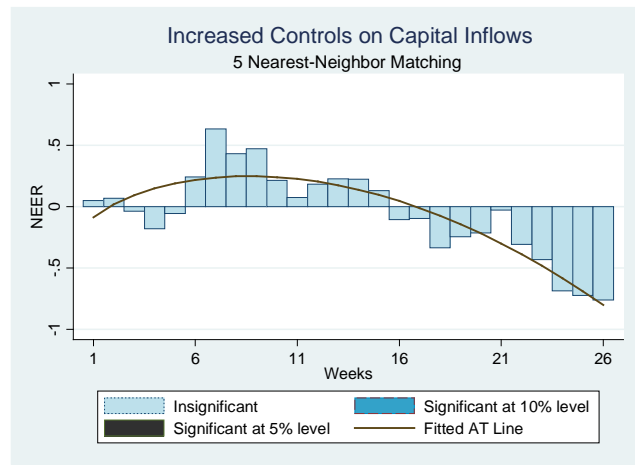

Decreased Controls on Capital Outflows

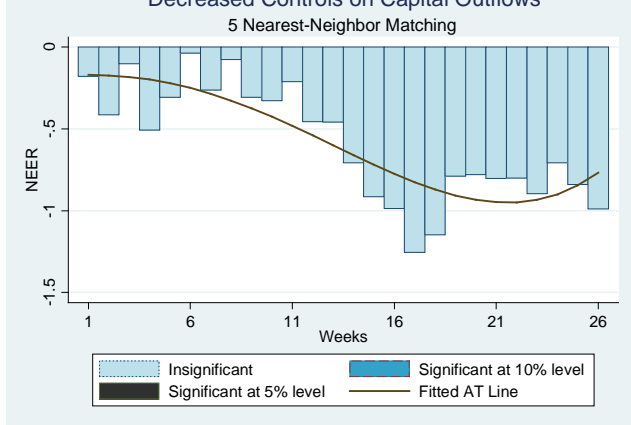

Increased Prudential Measures

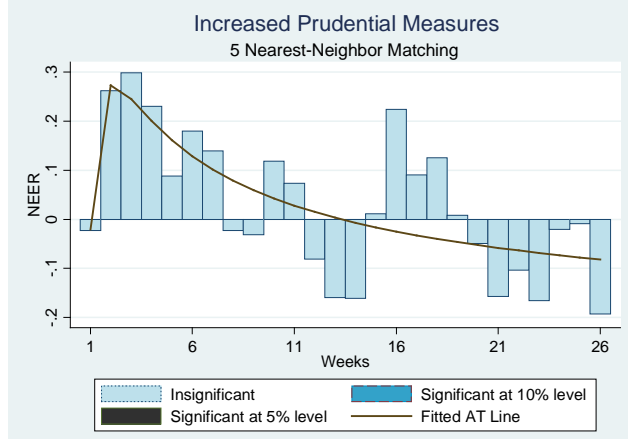

\% Change in Real Exchange Rate ${ }^{1}$

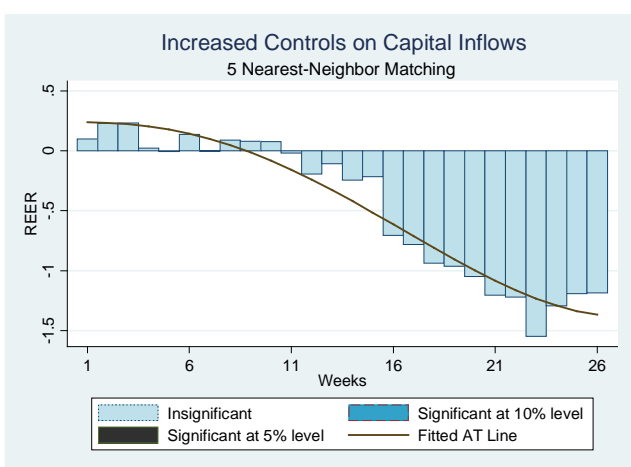

Decreased Controls on Capital Outflows

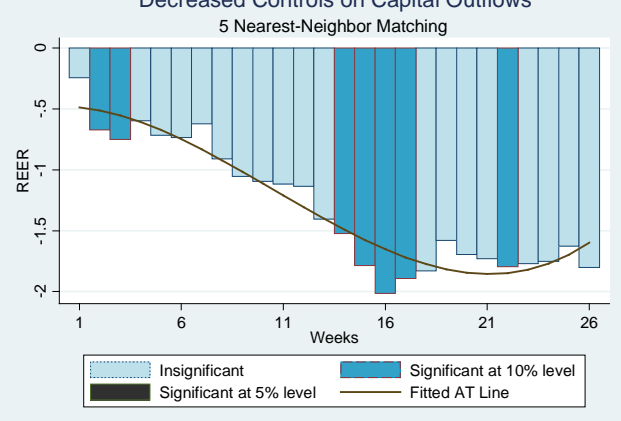

Increased Prudential Measures

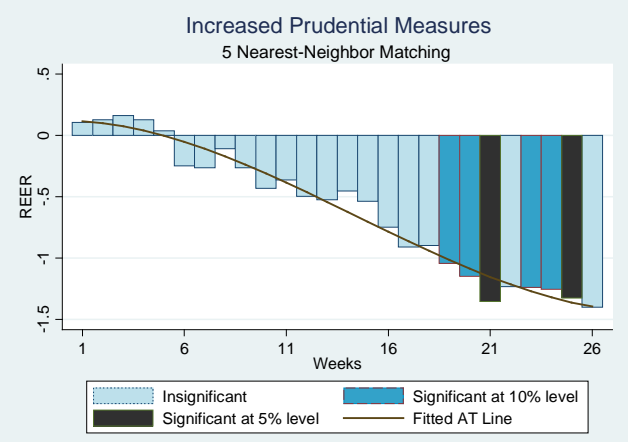

Change in Net Portfolio Inflows

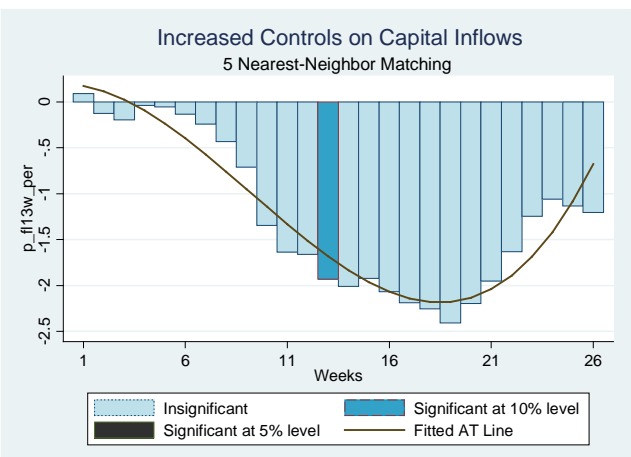

Decreased Controls on Capital Outflows

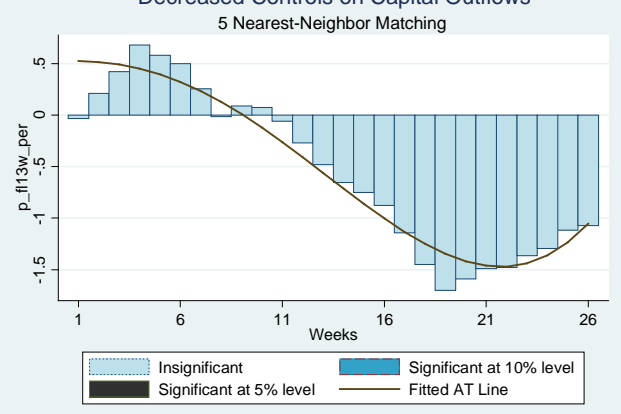

Increased Prudential Measures

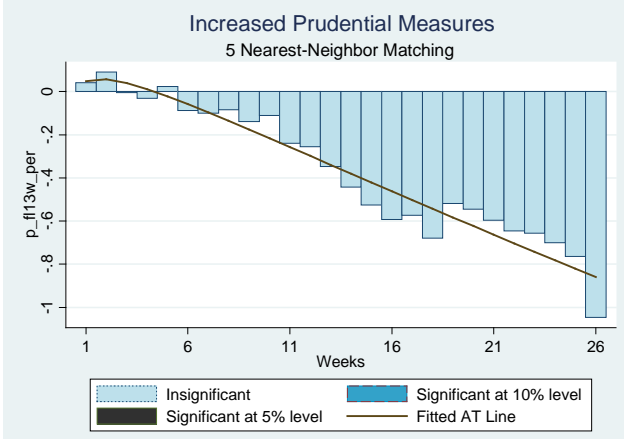

Notes: (1) Based on a broad exchange rate index. (2) Net portfolio inflows are cumulative flows over the last 13 weeks and measured as a percent of total portfolio assets lagged one period before the CFM event. 
Figure 3

\section{Average Treatment Effects of CFMs: Interest Rates, Equity Indices and Portfolio Flow Volatility}

Change in Interest Rate Differential

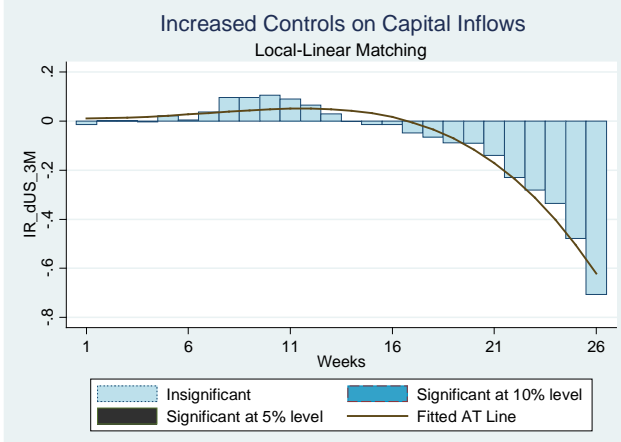

Decreased Controls on Capital Outflows

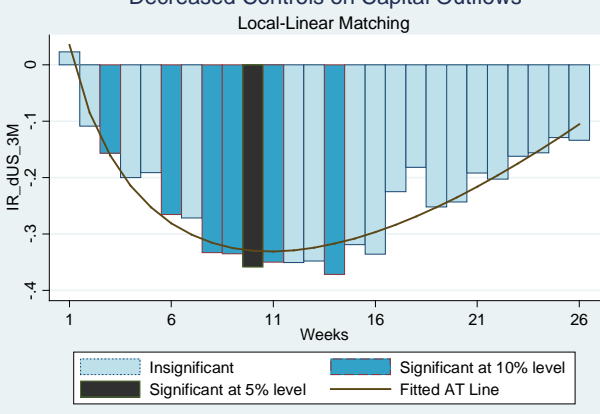

Increased Prudential Measures

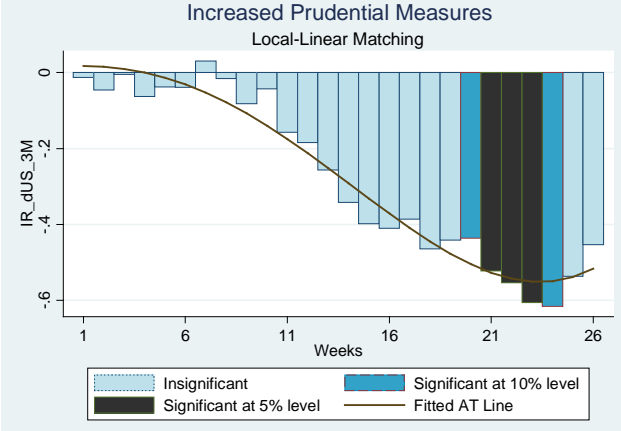

\% Change in Equity Index

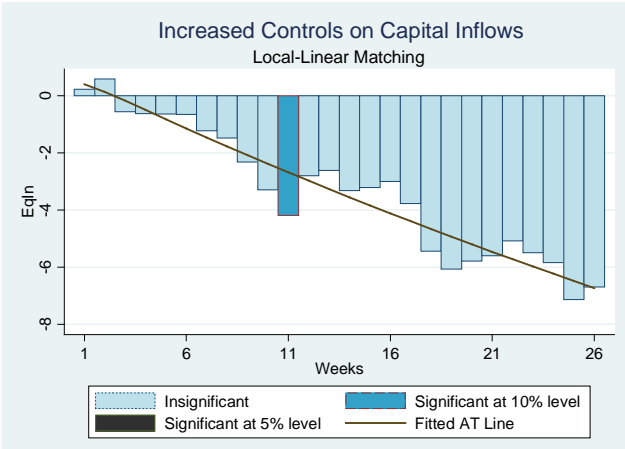

Decreased Controls on Capital Outflows

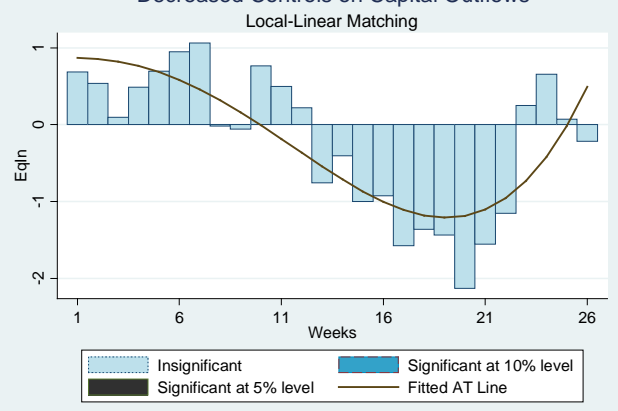

Increased Prudential Measures

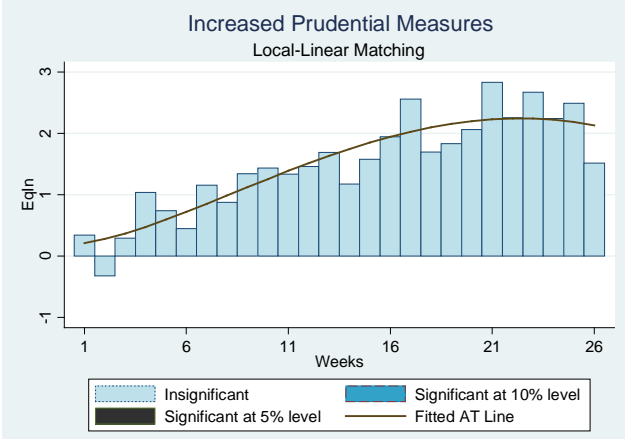

Volatility in Net Portfolio Inflows

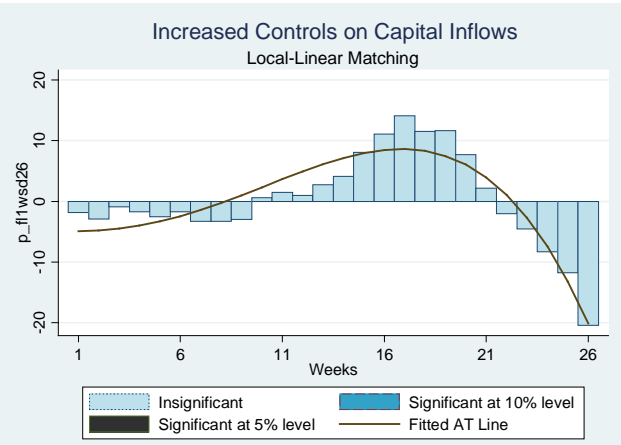

Decreased Controls on Capital Outflows

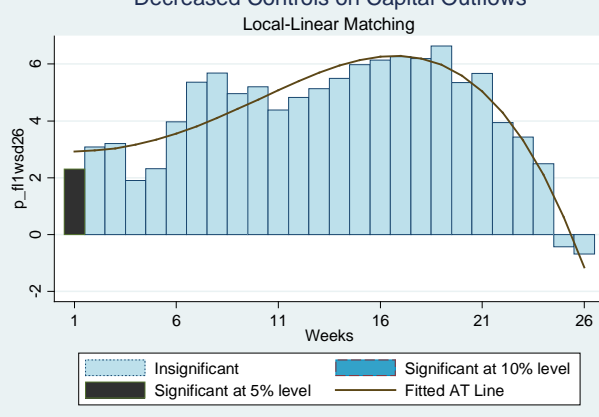

Increased Prudential Measures

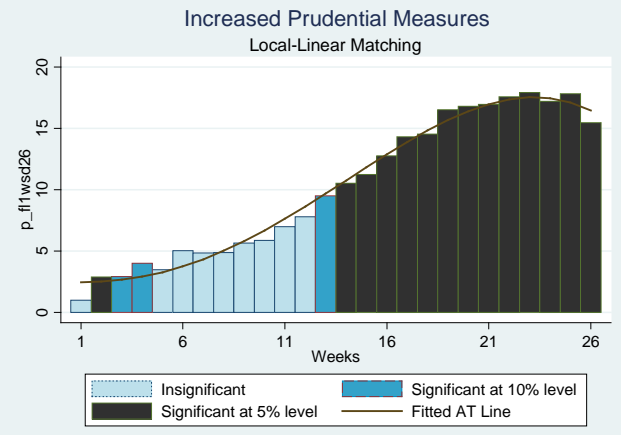

Notes: (1) Interest rate differential versus U.S. rate for 3-month Treasury bills. (2) Volatility of net portfolio inflows, defined as standard deviation over previous 26 weeks. 
Figure 4

\section{Average Treatment Effects of CFMs: Financial Vulnerabilities}

Change in Expected Inflation $\underline{\text { Increased Macroprudential Measures }}$

Increased Prudential Measures

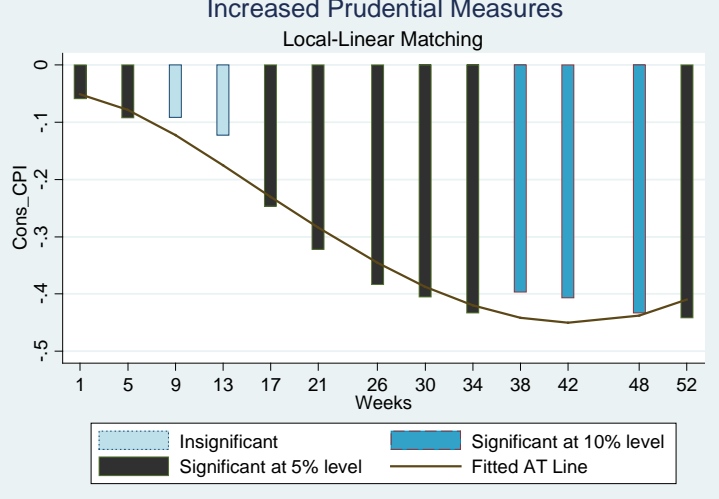

\% Change in Bank Leverage ${ }^{3}$ Increased Macroprudential Measures

Increased Prudential Measures Local-Linear Matching

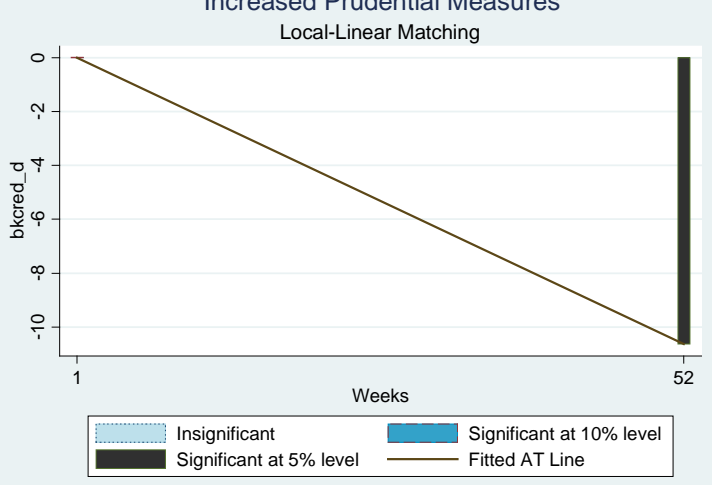

\% Change in Private Credit/GDP Increased Controls on Inflows

Increased Controls on Capital Inflows

$$
\text { Local-Linear Matching }
$$

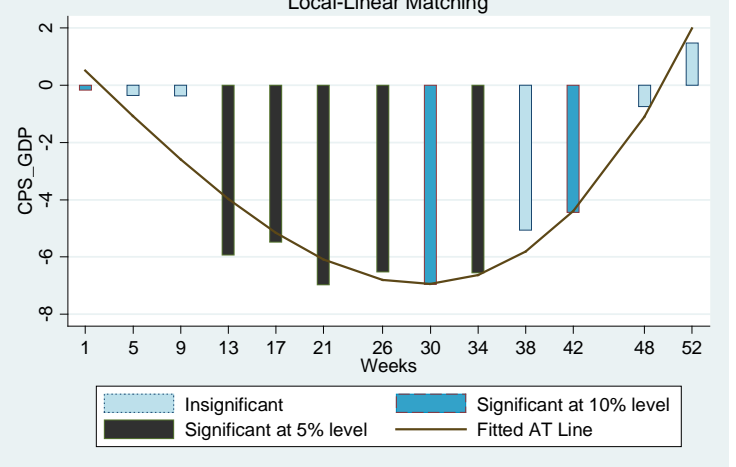

$\%$ Change in Bank Credit ${ }^{4}$ Increased Macroprudential Measures

Increased Prudential Measures Local-Linear Matching

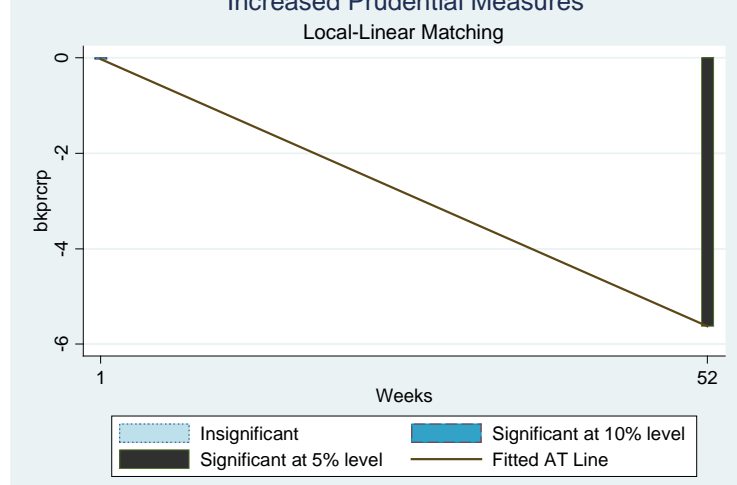

\% Change in Portfolio Share in Liabilities ${ }^{2}$ Increased Macroprudential Measures Increased Prudential Measures

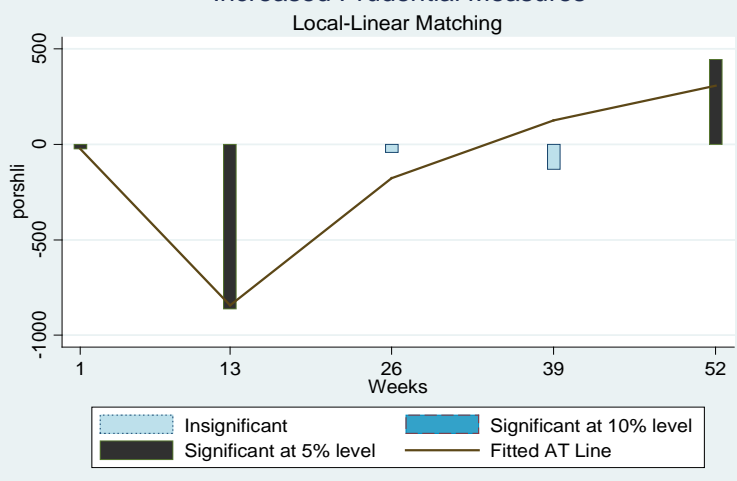

Notes: (1) Consensus inflation forecasts over the next year. (2) Portfolio investment liabilities as a share of total liabilities. (3) Bank leverage measured by ratio of bank credit to bank deposits. (4) Bank credit is private credit by deposit money banks and other financial institutions to GDP. 


\section{Figure 5}

\section{Average Treatment Effects of “Major” CFMs: Portfolio Flows, Volatility, and the Exchange Rate}

Change in Net Portfolio Inflows ${ }^{1}$

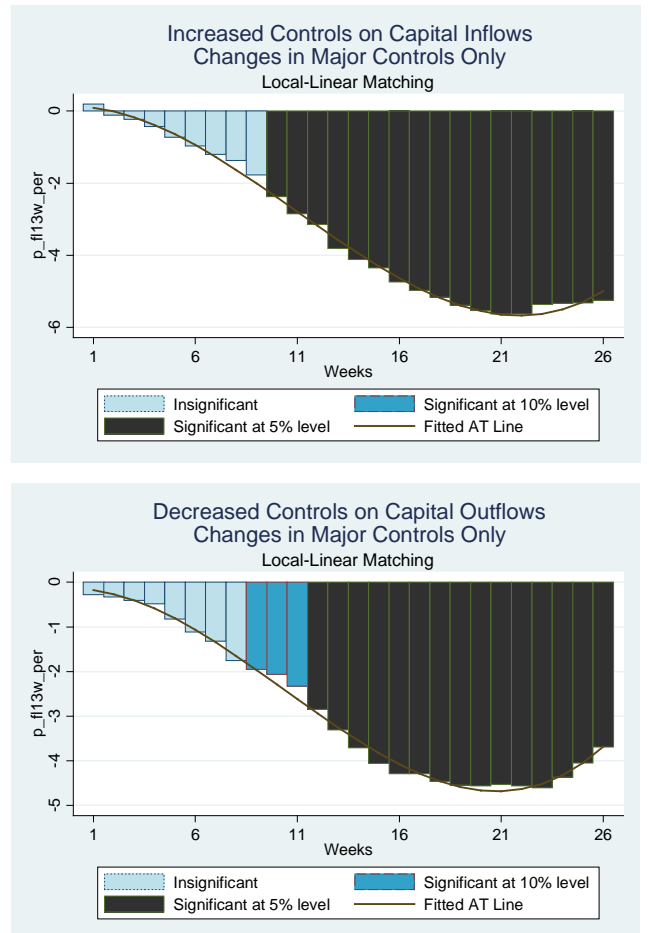

Change in Volatility of Net Portfolio Inflows

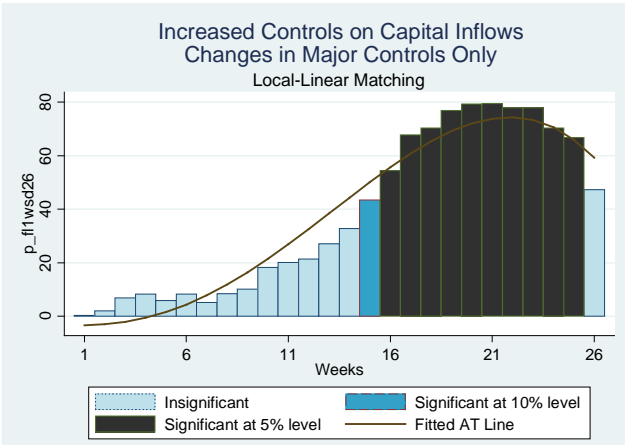

Decreased Controls on Capital Outflows Changes in Major Controls Only

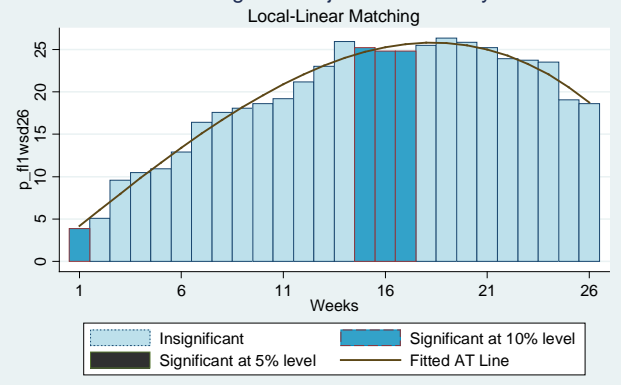

\% Change in Real Exchange Rate

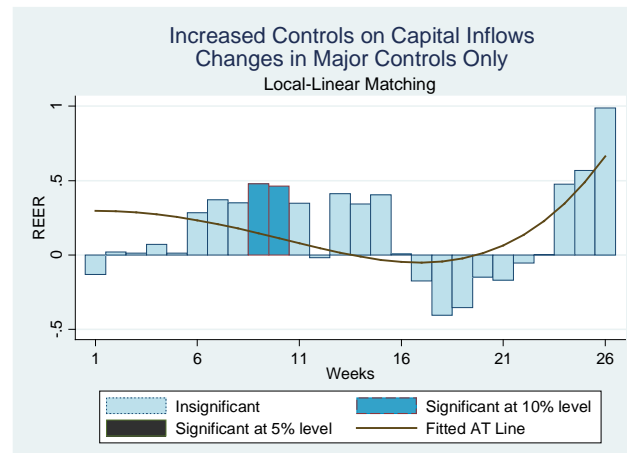

Decreased Controls on Capital Outflows Changes in Major Controls Only

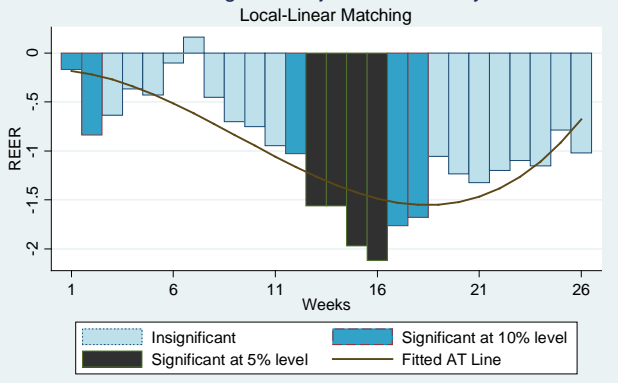

Notes: Major CFMs are changes in capital controls and macroprudential measures which received mention by financial analysts and in financial publications. (1) Net portfolio inflows are cumulative flows over the last 13 weeks and measured as a percent of total portfolio assets lagged one period before the CFM event. Volatility is measured as the standard deviation over the previous 26 weeks. 